\title{
WAGE BARGAINING AND MULTINATIONAL FIRMS IN GENERAL EQUILIBRIUM
}

\author{
CARSTEN ECKEL \\ HARTMUT EGGER
}

CESIFO WORKING PAPER NO. 1711

CATEgORY 7: TRADE POLICY

MAY 2006

Presented At CESIFo AREA CONFERENCE ON
GLOBAL ECONOMY, APRIL 2006
An electronic version of the paper may be downloaded
- from the SSRN website:
- from the RePEc website:
www.SSRN.com
- from the CESifo website:
www.RePEc.org
www.CESifo-group.de




\title{
WAGE BARGAINING AND MULTINATIONAL FIRMS IN GENERAL EQUILIBRIUM
}

\begin{abstract}
This paper studies the relationship between wage negotiations and the mode of foreign market penetration in a general equilibrium framework. We analyze the incentives of firms to set up a foreign production facility for improving their bargaining position vis-à-vis local unions. This renders the allocation of bargaining power among firms and unions a key determinant of the share of multinational enterprises and exporting firms. The economic mechanisms in this paper provide novel insights on how wages and unemployment rates adjust to economic integration. We distinguish between short-run effects for a given number of competitors and long-run effects after firm entry/exit. This allows us to identify possible globalization paths and to analyze their consequences for domestic labor markets.
\end{abstract}

JEL Code: F12, F15, F16, F23, J51.

Keywords: multinational firms, economic integration, wage bargaining, unemployment.

\author{
Carsten Eckel \\ University of Göttingen \\ Department of Economics \\ Platz der Göttinger Sieben 3 \\ 37073 Göttingen \\ Germany \\ carsten.eckel@wiwi.unigoettingen.de
}

\author{
Hartmut Egger \\ Socioeconomic Institute \\ University of Zurich \\ Zürichbergstr. 14 \\ 8032 Zurich \\ Switzerland \\ egger@wwi.unizh.ch
}

April 12, 2006

We are grateful to Markus Regez for excellent research assistance and we would like to thank participants at the 2006 CESifo Area Conference on Global Economy for helpful comments and suggestions. 


\section{Introduction}

The impact of globalization on domestic labor markets has sparked a lot of interest in both the popular press and the academic research. Recent empirical evidence has given support to the widespread concern that globalization tends to be harmful for (unskilled) labor in the industrialized world (cf. Feenstra and Hanson, 1999; Egger and Egger, 2003; and Hijzen, Görg and Hine, 2005). Motivated by the ongoing debate on adverse labor market developments, it is the goal of the present paper to shed light on the role of trade unions in the process of globalization. We study in how far wage bargaining provides an incentive for firms to become horizontally multinational and show how the bargaining power of unions determines the share of multinational enterprises in general equilibrium. In addition, we provide new insights on the role of multinational activity for wages and the unemployment rate. By distinguishing between short-run effects for a given number of competitors and long-run effects after firm entry/exit, we draw a comprehensive picture of the consequences of wage bargaining in a globalized world.

To develop our arguments, we set up a simple general equilibrium model with imperfect competition in the product market and wage bargaining in the labor market. We are interested in trade and investment relationships between industrialized economies. Therefore, we consider integration of two similar countries, which do not differ in their economic and political fundamentals. Focussing on identical economies renders our analysis different from the outsourcing literature, which emphasizes the incentives of firms to shift production abroad if a foreign country offers lower factor costs. Since the consequences of outsourcing from developed to developing countries are already well understood (Skaksen, 2004), we focus on the empirically more important case of two-way horizontal multinational activity. ${ }^{1}$ Furthermore, in order to isolate the impact of wage bargaining from other channels of influence, we assume that trade costs are zero. Then, a traditional proximity-concentration trade-off (Brainard, 1997) does not arise and exporting would be the preferred mode of foreign market penetration if labor markets were perfectly competitive. However, if wages are negotiated between firms and unions, there is a motive for setting up a foreign production facility, as this leads to a better outside option in the bargaining process.

It is a well established fact that the bargaining position of firms vis-á-vis trade unions depends on the firms' ability to shift production abroad (Gaston, 2002). A firm that sets up a second production site in a foreign economy can credibly threaten to replace domestic with foreign production if wage claims of unions are excessive. In the words of Caves (1996, p. 125): "If the MNE maintains capacity to produce the same goods in different national markets, output

\footnotetext{
${ }^{1}$ See Markusen (1984) for an early contribution and Markusen (2002) for a discussion on different forms of foreign direct investment (FDI) and their empirical support.
} 
curtailed by a strike in one market can be replaced from another subsidiary's plant."

The better outside opportunities of multinational (two-plant) producers lead to lower wage payments as compared to exporters. The associated reduction in variable production costs provides an incentive for firms to engage in foreign investment, even though it induces higher fixed costs. Hence, the decision to penetrate the foreign market through local affiliate production instead of exports depends on a trade-off between higher fixed and lower variable production costs. However, in contrast to the proximity-concentration trade-off the lower variable production costs do not accrue from a saving in real trade costs but rather from a better position in the wage bargain. Because the incentive to become multinational stems from the wage bargaining itself, the bargaining power of unions becomes a key determinant of firm structure. This is an important difference to the textbook models of multinational production, which build upon the assumption of perfectly competitive labor markets.

We are not the first to investigate foreign direct investment (FDI) under wage bargaining. Bughin and Vannini (1995) set up a partial equilibrium oligopoly model to analyze the impact of trade unions on a foreign firm's incentive to invest in the destination country. In a similar setting, Leahy and Montagna (2000) illustrate how different degrees of union centralization influence the attractiveness of locating in a host country. However, these studies do not account for the impact of FDI on the outside option of firms, because the wage rate in the multinational's parent country remains constant. The role of foreign investment for the bargaining position of firms is addressed in Zhao (1995) who studies the incentives for cross-hauling FDI under wage bargaining. Zhao (1998) presents an extension to a general equilibrium framework with full employment where the outside option of workers in the wage bargain is determined by the wage rate in a perfectly competitive sector. Zhao $(1995,1998)$ consider an integrated world market and allow for wage negotiations of multinational producers in the home and the host country. Skaksen and Sørensen (2001) choose a similar framework to analyze the conditions under which outbound foreign investment of a monopolist can be beneficial for domestic workers. Naylor and Santoni (2003) also account for wage bargaining in the home and the host country. They study an FDI game between a domestic and a foreign firm. Treating countries as segmented markets and ignoring exports as an option for serving foreign consumers, they find that FDI is less likely if unions are weak. ${ }^{2}$

In a recent contribution, Lommerud, Meland and Sørgard (2003) have investigated the role of trade liberalization for wage negotiations and firm location. They show that somewhat surprisingly an exogenous decline in trade costs can make FDI more attractive if domestic labor markets are unionized. Collie and Vandenbussche (2006) go one step further and analyze a

\footnotetext{
${ }^{2}$ Gaston (2002) associates a better outside option with economic integration. However, he does not investigate a firm's incentive to invest abroad, but rather treats variations in the outside options as an exogenous shock.
} 
country's optimal trade policy if foreign investment is possible and wages are set by unions. They show that a tariff may be welfare improving if it renders foreign investment unattractive and thereby saves union rents. Both of these studies do not allow for wage bargaining in the host country and treat the foreign wage as exogenous.

This paper differs from the existing literature in several important ways. First, we do not rely on a partial equilibrium framework but allow for general equilibrium feedback effects. This has important consequences for the outside options in the Nash bargain, which (although exogenous for the individual firm and union) are endogenously determined in equilibrium. Furthermore, a general equilibrium setting allows us to identify wage and (economy-wide) unemployment effects in a uniform framework. Second, by accounting for a mass of monopolistically competitive producers (instead of one or two competitors), we can ignore the integer problem and treat the share of multinational producers as a continuous variable. This gives us a comprehensive picture of how changes in the economic and political fundamentals affect the labor market outcome if firms can adjust their mode of foreign market penetration. Third, we investigate the decision of firms to enter and exit the market. This allows us to separate short-run effects for a given number of competitors from long run-effects, which are triggered by adjustments in the entry and exit decisions of producers. Finally, we are interested in the role of policy variables and shed light on the effectiveness of labor market reforms as a cure for the unemployment problem. ${ }^{3}$

The remainder of this paper is organized as follows. Section 2 outlines the theoretical framework and establishes the autarky equilibrium. In section 3, we study economic integration between two symmetric countries and discuss, for a given number of competitors, the short-run equilibrium under openness. Firm entry and exit decisions are at the agenda in section 4 . In section 5, we summarize the short-run and long-run labor market effects of economic integration. The last section concludes.

\section{Basic set-up: Wage bargaining under autarky}

We conduct our analysis in a model with two types of consumption goods, a horizontally differentiated good $x$ and a homogeneous good $Y$, and two factors of production (physical capital $K$ and labor $L$ ). Physical capital is inelastically supplied $(\bar{K})$ in a perfectly competitive factor market and the country is populated by a fixed number of workers $(\bar{L})$. Each worker is endowed with one unit of labor. The factor return to labor is negotiated between firms and unions. The respective wage-setting process is described in detail below.

\footnotetext{
${ }^{3}$ Note that Zhao (1998) also presents a general equilibrium framework. However, adding a competitive sector which uses labor input, he binds the outside option of workers to the competitive wage and cannot study unemployment effects. In addition, he assumes a duopoly in the industrial sector and does not provide insights into the consequences of firm entry.
} 
In the $x$-sector, firms have to invest $f$ units of capital to set up a production facility and to develop a blueprint for a variety of the differentiated good. Production of a distinct variety requires the input of labor. We normalize units so that one unit of the differentiated good requires the input of one unit of labor. Hence, the output of variety $i$ is determined by

$$
x(i)=\left\{\begin{array}{cl}
L(i) & \text { if } K(i) \geq f \\
0 & \text { if } K(i)<f
\end{array} .\right.
$$

Good $Y$ is a homogenous good, which is sold in a perfectly competitive market. Its production requires the input of capital only. For simplicity, we assume $Y=K_{Y}$. We choose good $Y$ as the numéraire, which implies that the factor price of capital, $r$, equals one: $r=1{ }^{4}$

Preferences of the representative consumer are given by a Cobb-Douglas utility function

$$
U=X^{\alpha} Y^{1-\alpha}, \quad 0<\alpha<1
$$

where $X \equiv\left[\int_{0}^{N} x(i)^{(\varepsilon-1) / \varepsilon} d i\right]^{\varepsilon /(\varepsilon-1)}$ is a CES-aggregator (Dixit and Stiglitz, 1977) and $\varepsilon \geq 2$ is a preference parameter that determines the elasticity of substitution between different product varieties. Here, $x(i)$ denotes the demand for variety $i$ and $N$ is the mass of producers in the $x$ sector. Each firm produces only a single variety, so that the mass of monopolistically competitive producers equals the mass of differentiated variants.

Utility maximization determines inverse demand for variety $i$ of the differentiated good:

$$
p(i)=(\alpha E / P)^{1 / \varepsilon} x(i)^{-1 / \varepsilon}
$$

where $E \equiv \bar{K}+\int_{0}^{N} p(i) x(i) d i$ is total income and $P \equiv \int_{0}^{N} p(i)^{1-\varepsilon} d i$ is a price index. Profits are given by

$$
\pi(i)=(\alpha E / P)^{1 / \varepsilon} x(i)^{1-1 / \varepsilon}-w(i) x(i)-f .
$$

Firms take aggregate variables as given and hire workers until their marginal return equals the wage rate. This implies

$$
w(i)=(1-1 / \varepsilon)(\alpha E / P)^{1 / \varepsilon} x(i)^{-1 / \varepsilon}
$$

Equation (5) determines the optimal scale of firm $i$ for a given $E, P$ and $w(i)$. Note also that

\footnotetext{
${ }^{4}$ The introduction of a separate numéraire sector is motivated by Krugman's (1991) seminal work on economic geography. The assumption on factor use in the two production sectors is primarily made for tractability reasons. Together, these two ingredients allow us to solve the model analytically and to present the main economic mechanisms in a transparent way.
} 
the price-cost margin depends on $\varepsilon$ only:

$$
w(i) / p(i)=(1-1 / \varepsilon)
$$

To account for the fact that institutions shape the labor markets of the industrial world, we consider trade unions. These trade unions bargain over wages for their members. Wage negotiations take place at the firm level and union activities are restricted to a single producer. Hence, there is a mass of $N$ firm-union bargaining pairs. Wage rate $w(i)$ is determined in a Nash bargain by solving the following maximization problem

$$
\max _{w(i), x(i)} \Omega(w(i), x(i))=\{x(i)[w(i)-\bar{w}]\}^{\gamma}\{\pi(i)-\bar{\pi}\}^{1-\gamma}, \text { s.t. } d \pi(i) / d x(i)=0
$$

Variable $\bar{w}$ denotes the outside option of a worker (independent of the firm where he/she is employed) and $x(i)[w(i)-\bar{w}]$ gives union $i$ 's contribution to the Nash product (recall $x(i)=$ $L(i)$ from (1)). In analogy, $\bar{\pi}$ denotes the outside option of firms and $\pi(i)-\bar{\pi}$ is firm $i$ 's contribution to the Nash product. Parameters $\gamma$ and $(1-\gamma)$ indicate the bargaining power of unions and firms, respectively. Of course, $\gamma \in[0,1]$. If $\gamma=0$, unions have no bargaining power and we end up in the borderline case of a perfectly competitive labor market. In contrast, $\gamma=1$ indicates a situation, where firms do not have any impact on the wage level, which is dictated by unions.

Wage negotiations begin after firms have decided to enter, i.e. after the costs of developing a blueprint and setting up a local production facility have been incurred. With $r=1$, these costs are given by $f$. Hence, fixed costs $f$ are sunk when bargaining takes place, implying $\bar{\pi}=-f$. Firms have the "right-to-manage" employment, so that maximizing the Nash product is subject to condition (5). The solution to the bargaining problem in (7) is the so called wage setting curve. It gives the wage premium paid to workers in firm $i$ over their outside option as a function of the output (or employment) level of the firm: ${ }^{5}$

$$
w(i)-\bar{w}=\frac{\varepsilon-1}{\varepsilon} \frac{\gamma}{\varepsilon-1+\gamma}\left(\frac{\alpha E}{P}\right)^{1 / \varepsilon} x(i)^{-1 / \varepsilon}
$$

Equations (5) and (8) jointly determine the bargaining outcome for given aggregate variables $E, P$, and $\bar{w}$ :

$$
\begin{gathered}
x(i)=\left((1-1 / \varepsilon) \frac{\varepsilon-1}{\varepsilon-1+\gamma} \bar{w}^{-1}\right)^{\varepsilon}(\alpha E / P), \\
w(i)=\frac{\varepsilon-1+\gamma}{\varepsilon-1} \bar{w}
\end{gathered}
$$

\footnotetext{
${ }^{5}$ See the Appendix for a derivation of the wage-setting curve in (8).
} 
Since all producers and unions are identical we can omit firm indices in the following: $w(i)=w$ and $x(i)=x$ for all $i \in[0, N]$.

Outside options of workers depend on wages attainable outside the firms, unemployment benefits and the unemployment rate. Unemployment benefits are financed by lump-sum taxes. In a symmetric autarky equilibrium with identical firm-union bargaining pairs, the outside option of a worker is given by

$$
\bar{w}=(1-u) w+u \beta w
$$

where $\beta \in(0,1)$ is the replacement ratio and $u$ is the unemployment rate. ${ }^{6}$ From (10) and (11), we obtain the autarky rate of unemployment $u_{a}$ :

$$
u_{a}=\frac{1}{1-\beta} \frac{\gamma}{\varepsilon-1+\gamma}
$$

(Subscript $a$ indicates autarky equilibrium values.) The requirement of $u \in(0,1)$ imposes a restriction on the replacement ratio $\beta$ : $\beta<(\varepsilon-1) /(\varepsilon-1+\gamma)$. A higher $\gamma$ is associated with stronger unions and leads to higher wage claims in the Nash bargain. In equilibrium, this results in higher unemployment rates. A higher replacement ratio $\beta$ leads, for a given wage rate, to higher unemployment benefits and thus to a better outside option of workers in the Nash bargain. This also raises wage claims and the equilibrium unemployment rate. The unemployment rate is independent of factor endowments and the wage rate because unemployment benefits are proportional to $w$ and the production technology is linear in $L$ (Beissinger and Egger, 2004).

Aggregate output of differentiated goods depends on aggregate employment: $N x=(1-u) \bar{L}$. Hence, firm size can be written as

$$
x_{a}^{\prime}=\left(1-u_{a}\right) \bar{L} / N
$$

For now, we assume that the mass of producers $N$ is exogenously given, so that $x_{a}^{\prime}$ can be interpreted as the equilibrium firm size in the short run, i.e. before entry or exit takes place. (A prime denotes a short run variable.) Entry and exit of firms will be analyzed below.

The capital market equilibrium requires

$$
\bar{K}=Y+N f,
$$

so that the output of the homogenous good is determined by $Y_{a}^{\prime}=\bar{K}-N f$. Since entry and exit decisions are treated as exogenous for the moment, we have to assume a sufficiently small

\footnotetext{
${ }^{6}$ See Gaston (2002) for a similar specification.
} 
firm number, with $N<\bar{K} / f$, to obtain $Y_{a}^{\prime}>0 .{ }^{7}$ With Cobb-Douglas preferences, expenditure shares devoted to $X$ and $Y$ are constant: $Y=(1-\alpha) E$ and $p x N=\alpha E$. Hence,

$$
E_{a}^{\prime}=\frac{\bar{K}-N f}{1-\alpha}
$$

and

$$
p_{a}^{\prime}=\frac{\alpha}{1-\alpha} \frac{(\bar{K}-N f)}{\left(1-u_{a}\right) \bar{L}} .
$$

Using (6), the wage rate can be expressed as

$$
w_{a}^{\prime}=\frac{\alpha(\varepsilon-1)}{(1-\alpha) \varepsilon} \frac{(\bar{K}-N f)}{\left(1-u_{a}\right) \bar{L}} .
$$

Note that wage rate $w_{a}^{\prime}$ also determines the factor price differential $w / r$, as $r=1$. Finally, by virtue of (3)-(6), profits can be expressed as

$$
\pi_{a}^{\prime}=\frac{1}{\varepsilon} \frac{\alpha}{(1-\alpha)} \frac{\bar{K}-N f}{N}-f
$$

Equations (12)-(18) provide the short run equilibrium solutions. An increase in the endowment with capital raises income $E$, output of $Y$, prices $p$, wages $w$ and profits $\pi$. However, it does not affect output of the differentiated good $x$. An increase in the endowment with labor increases $x$, but reduces $p$ and $w$. The fall in $w$ is proportional to the increase in $\bar{L}$ so that total income and profits remain unaffected. It is an important feature of our model that changes in market size variables $\bar{K}$ and $\bar{L}$ do not have an impact on the equilibrium unemployment rate $u_{a}$. This is consistent with the stylized fact that unemployment rates do not exhibit a size pattern, i.e. unemployment is a problem in both large and small economies. An increase in the mass of firms $N$ fosters competition and tends to reduce output per firm. Since $x_{a}^{\prime}$ declines proportionally, total market output $N x$ and unemployment rate $u_{a}$ remain unaffected. Changes in fixed costs $f$ exhibit a similar effect.

All else equal, a higher $\beta$ or $\gamma$ raises the factor return negotiated in the wage bargain, according to (8) and (11). Due to a constant markup rule, this raises the price level and therefore leads to a lower demand. As a consequence, firms lay off workers to reduce their scale. This raises unemployment and the aggregate output level $N x$ declines. The two opposing effects on price $p_{a}^{\prime}$ and output $x_{a}^{\prime}$ exactly cancel out, leaving total income $E$ unaffected by $\beta$ and $\gamma$ changes. From (12) and (17) we can conclude that a policy intervention that reduces $\beta$

\footnotetext{
${ }^{7}$ Under free entry and exit of producers, the firm number will adjust endogenously, such that diversification in the production pattern is guaranteed, see (19) below.
} 
or $\gamma$ is a cure for high unemployment rates but at the same time induces lower wages. This reveals a potential conflict of labor market reforms that aim at reducing the unempoyment rate. Furthermore, since the aggregate income is independent of $\beta$ and $\gamma$, such reforms are also less successful an instrument for raising the GDP level.

In the long run, positive profits induce entry. Hence, the long run equilibrium is characterized by zero profits and the mass of firms is given by

$$
N_{a}^{\prime \prime}=\frac{\alpha}{(\alpha+\varepsilon(1-\alpha))} \frac{\bar{K}}{f}
$$

according to (18). (A double prime denotes the long run equilibrium outcome.) An increase in $\bar{K}$ is associated with larger demand for intermediate goods and renders entry of additional producers attractive. Moreover, a reduction in $f$ raises profits and leads to additional entry, as well. Hence, it is intuitive that the mass of firms must be rising in $\bar{K} / f$.

Substituting (19) into (13)-(17) yields the long run free entry solutions:

$$
\begin{gathered}
x_{a}^{\prime \prime}=\frac{(\alpha+\varepsilon(1-\alpha))}{\alpha} \frac{\left(1-u_{a}\right) f \bar{L}}{\bar{K}} \\
E_{a}^{\prime \prime}=\frac{\varepsilon}{(\alpha+\varepsilon(1-\alpha))} \bar{K} \\
p_{a}^{\prime \prime}=\frac{\alpha \varepsilon}{(\alpha+\varepsilon(1-\alpha))} \frac{\bar{K}}{\left(1-u_{a}\right) \bar{L}} \\
w_{a}^{\prime \prime}=\frac{\alpha(\varepsilon-1)}{(\alpha+\varepsilon(1-\alpha))} \frac{\bar{K}}{\left(1-u_{a}\right) \bar{L}}
\end{gathered}
$$

The output of the homogenous good is given by $Y_{a}^{\prime \prime}=[\varepsilon(1-\alpha) /(\alpha+\varepsilon(1-\alpha))] \bar{K}$. This completes our discussion of the autarky equilibrium.

\section{Wage-bargaining under openness: a short-run perspective}

We now turn to the role of trade unions in an international environment. For this purpose, we consider two identical economies $(H, F)$ with segmented factor markets. Firms have two options for serving consumers in the foreign country. On the one hand, they can penetrate foreign markets as an exporter (subscript $n$ ) by producing all goods at home and shipping exports to consumers abroad. On the other hand, they can set up a second production plant abroad and serve foreign consumers from a local subsidiary. Because the two production sites provide identical goods, we refer to such a firm as a horizontal multinational enterprise (MNE, subscript $m)$. 
To emphasize the role of trade unions for the internationalization strategy (i.e., the mode of foreign market penetration), we eliminate other determinants of the export versus foreign investment decision from our model. In particular, we assume that exporters and multinationals share the same production technology and that there are no trade frictions. The underlying reason for these simplifications is that neither the proximity concentration trade-off nor productivity differences are the focus of our analysis. These issues are well understood and there is profound empirical evidence for their importance (see Brainard, 1997).

Our focus is on the role of wage bargaining. Without productivity differences or trade-cost savings, multinational enterprises face a pure fixed cost disadvantage when labor markets are perfectly competitive. However, in the presence of unions, there can be a motive for operating a second production facility: outside option. If wage bargaining fails in one country, the MNE can service this market from its production facility abroad. This outside option improves its bargaining position vis-á-vis the union. As a consequence, multinational producers can enforce lower wages than exporting firms because an exporter cannot relocate its production across borders.

A prerequisite for this mechanism is that firms can run production facilities outside the range of influence of domestic unions. In an international context, it is a realistic assumption that unions are strictly national and cannot enforce any wage contract beyond borders. This leads to plant-level wage negotiations if labor markets are unionized and a firm operates one production plant at home and a second one abroad.

We assume that investment decisions and formation of trade unions in foreign subsidiaries of multinationals take place before the wage bargain. The inverse demand function in $H$ and $F$ are represented by (3). Profits of exporters $(n)$ and multinationals $(m)$ with headquarters in country $j \neq k$ are given by

$$
\begin{array}{r}
\pi_{n}^{j}(i)=\left(\alpha E^{j} / P^{j}\right)^{1 / \varepsilon} x_{n}^{j}(i)^{1-1 / \varepsilon}+\left(\alpha E^{k} / P^{k}\right)^{1 / \varepsilon} x_{n}^{k}(i)^{1-1 / \varepsilon} \\
-w_{n}^{j}(i)\left[x_{n}^{j}(i)+x_{n}^{k}(i)\right]-f, \\
\pi_{m}^{j}(i)=\left(\alpha E^{j} / P^{j}\right)^{1 / \varepsilon} x_{m}^{j}(i)^{1-1 / \varepsilon}+\left(\alpha E^{k} / P^{k}\right)^{1 / \varepsilon} x_{m}^{k}(i)^{1-1 / \varepsilon} \\
-w_{m}^{j}(i) x_{m}^{j}(i)-w_{m}^{k}(i) x_{m}^{k}(i)-\rho f,
\end{array}
$$

respectively.

Setting up a second production facility induces additional fixed costs $(\rho-1) f>0$. The parameter $\rho>1$ captures the fixed cost disadvantage of multinational enterprises. The existing 
literature gives no clearcut prediction on the size of $\rho$. If providing headquarters services (which include the development of the blueprint) is costless, and fixed costs for setting up production facilities are proportional to the number of plants, $\rho=2$ is a meaningful assumption. In contrast, if providing headquarters services induces costs, the increase in the fixed cost may be less than proportional when the firm sets up a second production plant. This leads to $1<\rho<2$. Finally, Helpman, Melitz and Yeaple (2004) emphasize that setting up a foreign subsidiary induces higher fixed costs than setting up a local plant. ${ }^{8}$ This leads to $\rho>2$ in our terminology.

However, the fixed cost differential is not the only difference between exporting firms and multinational enterprises. Because existence of a foreign subsidiary also affects the outside option of firms in the Nash bargain, wages will be lower for MNEs than for exporters: $w_{n}^{j}(i)>w_{m}^{j}(i) .^{9}$ This trade-off between higher fixed and lower variable costs under multinational production is in the center of our interest and will be analyzed in detail below. At this point we introduce some symmetry assumptions to simplify the formal exposition. First, we assume that the two economies are symmetric, so that we can suppress country indices. Moreover, we assume that producers of the same type (exporter or multinational) are identical. Hence, we can omit firm indices as well.

Let us now turn to the wage-bargaining problem. Since firms have the "right-to-manage" employment, they will choose the number of workers such that the marginal product of labor equals the wage rate. This is taken into account in the Nash bargain. If a firm is an exporter, the outcome of the firm-level negotiation is determined by maximization problem (7) and the respective wage-setting curve is given by ${ }^{10}$

$$
w_{n}-\bar{w}=\frac{(1-1 / \varepsilon) \gamma}{\varepsilon-1+\gamma}\left(\frac{\alpha E}{P}\right)^{1 / \varepsilon} x_{n}^{-1 / \varepsilon} .
$$

However, if a firm sets up an affiliate abroad, it can serve the home market through exports from the foreign production plant. Then, the outside option of a multinational enterprise in the Nash bargain is $\bar{\pi}_{m}=\pi_{n}-(\rho-1) f$, where $\pi_{n}$ represents the profits of servicing the domestic market from the foreign production facility as an exporter. Because of symmetry, this is the same profit that a domestic exporter can make. ${ }^{11}$ Substituting $\bar{\pi}_{m}$ in (7), the outcome of the

\footnotetext{
${ }^{8}$ Better knowledge of the domestic distribution system may be one explanation for this fixed cost differential.

${ }^{9}$ Note that $w_{n}^{j}(i)>w_{m}^{j}(i)$ is not contradictory to the empirical finding that multinational firms pay higher wages. If multinational producers have better technological (or organizational) characteristics, like higher productivity levels, rent-sharing mechanisms can explain the empircal pattern of factor returns (see Barth and Zweimüller, 1995; Blanchflower, Oswald and Sanfey, 1996; Hildreth and Oswald, 1997). These sources of higher wage payments of multinational firms are eliminated in our analysis by the assumption of identical production technologies.

${ }^{10}$ See the Appendix for a derivation of the wage-setting curve in (26).

${ }^{11}$ For a discussion on the outside option of a multinational producer, see the Appendix. A detailed derivation of the wage-setting curve in (27) can also be found there.
} 
wage bargain between a union and a multinational firm (at the plant-level) is given by

$$
w_{m}-\bar{w}=\frac{2(1-1 / \varepsilon) \gamma\left[1-\theta^{1-1 / \varepsilon}\right]}{2 \varepsilon \gamma\left[1-\theta^{1-1 / \varepsilon}\right]+(1-\gamma)(\varepsilon-1)}\left(\frac{\alpha E}{P}\right)^{1 / \varepsilon} x_{m}^{-1 / \varepsilon},
$$

where $\theta \equiv x_{n} / x_{m}$ is the output disadvantage ratio of an exporter vis-á-vis a multinational firm.

If the two types of producers (exporters and multinationals) coexist, the first-order conditions of profit-maximization yield

$$
w_{n}=(1-1 / \varepsilon)(\alpha E / P)^{1 / \varepsilon} x_{n}^{-1 / \varepsilon}, \quad w_{m}=(1-1 / \varepsilon)(\alpha E / P)^{1 / \varepsilon} x_{m}^{-1 / \varepsilon},
$$

respectively, according to (5). Together with (26) and (27), the two expressions in (28) provide the partial equilibrium solution for $x_{n}, x_{m}, w_{n}$ and $w_{m}$. They imply

$$
\begin{aligned}
w_{n} & =\frac{\varepsilon-1+\gamma}{\varepsilon-1} \bar{w} \\
w_{m} & =\frac{2 \varepsilon \gamma\left(1-\theta^{1-1 / \varepsilon}\right)+(1-\gamma)(\varepsilon-1)}{\left[2 \gamma\left(1-\theta^{1-1 / \varepsilon}\right)+(1-\gamma)\right](\varepsilon-1)} \bar{w}
\end{aligned}
$$

respectively. And they also determine

$$
\theta=\left(\frac{w_{m}}{w_{n}}\right)^{\varepsilon}
$$

which shows that the ratio of output levels depends on the inverse ratio of wages. If multinational firms are able to negotiate lower wages $\left(w_{m}<w_{n}\right)$, they enjoy a higher output level $\left(x_{m}>x_{n}\right)$, according to (31).

Equations (29)-(31) provide an implicit solution for $\theta \in(0,1]:^{12}$

$$
\Gamma(\theta, \gamma) \equiv \frac{2 \gamma\left[1-\theta^{1-1 / \varepsilon}\right]}{2 \varepsilon \gamma\left[1-\theta^{1-1 / \varepsilon}\right]+(1-\gamma)(\varepsilon-1)}+\frac{\varepsilon-1}{\varepsilon-1+\gamma} \theta^{-1 / \varepsilon}-1=0 .
$$

The main properties of $\theta$ are summarized in lemma 1 :

Lemma 1 Consider $\varepsilon \geq 2$. Then, $\Gamma(\theta, \gamma)=0$ determines a continuous and twice differentiable function $\theta=\tilde{\theta}(\gamma)$ on interval $[0,1)$, which has the following properties: (i) $\tilde{\theta}(0)=1$ and $\tilde{\theta}(\gamma)<1$ for any $\gamma \in(0,1)$; (ii) $\lim _{\gamma \rightarrow 1} \tilde{\theta}(\gamma)=1$; and (iii) $\tilde{\theta}(\gamma)$ has a unique minimum at some $\gamma^{*} \in(0,1)$, so that $d \tilde{\theta}(\cdot) / d \gamma<0$, for any $\gamma \in\left(0, \gamma^{*}\right)$, and $d \tilde{\theta}(\cdot) / d \gamma>0$, for any $\gamma \in\left(\gamma^{*}, 1\right)$.

\footnotetext{
${ }^{12}$ If $\theta>1$, two plant production gives rise to a disadvantage in both variable and fixed production costs. Then, multinational activities are definitely unattractive (see (45) below), so that we can safely ignore this case in the following analysis.
} 
Proof. See the Appendix.

Figure 1 illustrates the $\tilde{\theta}(\gamma)$-function for $\varepsilon=2 .{ }^{13}$ The shape of the $\tilde{\theta}$ function is the result of two counteracting effects. First, an increase in the bargaining power of unions $\gamma$ raises the wage rate determined in the Nash bargain. This wage increase is lower if a multinational firm and a union negotiate, because a multinational firm has a higher outside option than an exporting firm. As a consequence, the wage differential $w_{m} / w_{n}$ is reduced and $\theta$ falls. Second, an increase in $\gamma$ lowers the weight of a firm's contribution to the Nash product, so that the gap in the outside options of exporters and multinationals becomes less important. This effect lowers the wage differential and leads to a positive impact of $\gamma$ on $\theta$. It is the interplay of these two opposing effects, which explains the shape of the $\tilde{\theta}(\gamma)$-locus in figure 1. If $\gamma$ is low $\left(\gamma<\gamma^{*}\right)$, and the weight of a firm's contribution to the Nash product is large, the first effect dominates, while the second effect is stronger if $\gamma$ is large $\left(\gamma>\gamma^{*}\right)$.

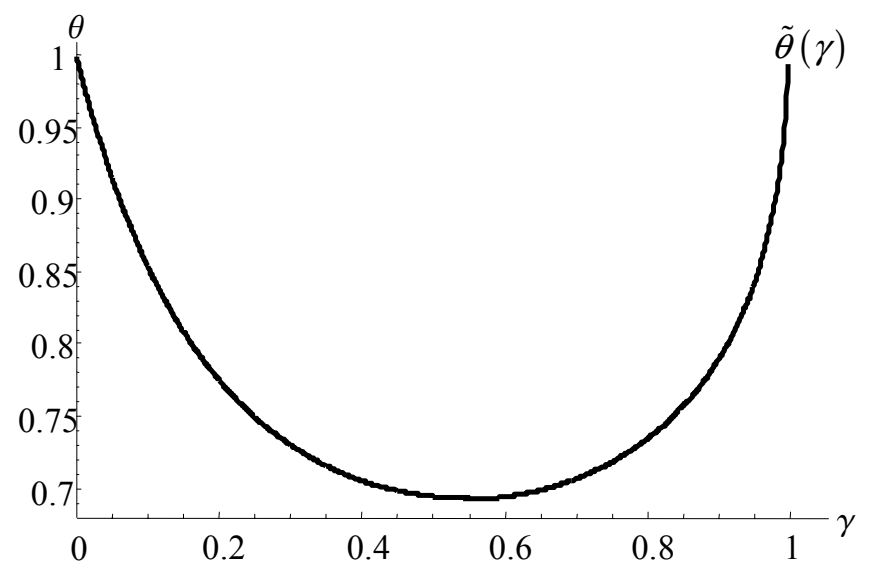

Figure 1: The impact of bargaining power parameter $\gamma$ on relative firm size $\theta$

In a next step, we can explicitly solve for outside option $\bar{w}=(1-u(1-\beta)) \tilde{w}$, where

$$
\tilde{w} \equiv \frac{m x_{m} w_{m}+(N-m) x_{n} w_{n}}{m x_{m}+(N-m) x_{n}}
$$

is the average wage rate in the two economies (see (11)). Using $x_{n} / x_{m}=\theta$ and $w_{m} / w_{n}=\theta^{1 / \varepsilon}$ from above and denoting by $\mu \equiv m / N$ the share of multinational firms in the overall mass of producers, (33) simplifies to

$$
\tilde{w}=w_{m} \frac{\mu+(1-\mu) \theta^{1-1 / \varepsilon}}{\mu+(1-\mu) \theta}
$$

\footnotetext{
${ }^{13}$ Of course, the output ratio $\theta$ also depends on the size of the preference parameter $\varepsilon$ but it is independent of all other economic fundamentals. Preference parameter $\varepsilon$ is suppressed as an argument of $\tilde{\theta}$, since its role is not of interest in the subsequent analysis.
} 
Thus, the outside option of unions as a function of firm structure variable $\mu$ is given by

$$
\bar{w}=(1-u(1-\beta)) w_{m} \frac{\mu+(1-\mu) \theta^{1-1 / \varepsilon}}{\mu+(1-\mu) \theta} .
$$

Using equations (29) and (35) together with $w_{m} / w_{n}=\theta^{1 / \varepsilon}$, we can determine the equilibrium unemployment rate as a function of $\mu$ and $\theta$ :

$$
u=\frac{1}{(1-\beta)}\left(1-\frac{\varepsilon-1}{\varepsilon-1+\gamma} \frac{\mu+(1-\mu) \theta}{\mu \theta^{1 / \varepsilon}+(1-\mu) \theta}\right) .
$$

Thereby, $u>0$ holds for any $\gamma>0$, while $u<1$ requires that $\beta$ is sufficiently low. It can be shown that $\beta<(\varepsilon-1) /(\varepsilon-1+\gamma)$ is sufficient for $u<1$, irrespective of the share of multinational firms $\mu$ and the output ratio $\theta$ (see our discussion below (12)). ${ }^{14}$ Moreover, since a mass of $N$ producers is active in each economy, aggregate employment equals $2 N x_{m}(\mu+(1-\mu) \theta)=(1-u) \bar{L}$, and the output of a multinational firm is given by

$$
x_{m}=\frac{(1-u) \bar{L}}{2 N(\mu+(1-\mu) \theta)} .
$$

Equation (37) expresses a multinational's plant level scale as a function of overall economic activity $(1-u) \bar{L}$, the mass of competitors $2 N$, the share of multinational producers $\mu$ and the output ratio $\theta$. Ceteris paribus, a higher unemployment rate lowers aggregate employment and thus output at the firm level. Furthermore, since exporters produce at a lower scale than MNEs, a higher $\mu$ fosters competition and, all other things equal, reduces $x_{m}$. Finally, a higher $\theta$ is associated with lower employment of multinational firms relative to exporters and therefore reduces $x_{m}$ for a given rate of unemployment $u$. The corresponding output of an exporting firm can be calculated using $x_{n}=\theta x_{m}$.

By following the same route as in the previous section, we can solve for the remaining general equilibrium variables. The capital market clearing condition implies

$$
\bar{K}=Y+(1+\mu(\rho-1)) N f .
$$

It determines the output of $Y$ as a function of $\mu$ and $N: Y=\bar{K}-(1+\mu(\rho-1)) N f$. Again, we assume a sufficiently small $N$, such that $Y$ is positive (for any $\mu$ ), see our discussion below (14)

\footnotetext{
${ }^{14}$ It can be shown that $d u / d \mu<0$. Then, noting that $\beta<(\varepsilon-1) /(\varepsilon-1+\gamma)$ is sufficient for $\left.u\right|_{\mu=0}<1$, it is obvious that $u<1$ holds for any possible $\mu$. Furthermore, evaluating $u$ at $\mu=1$, we can conclude that $u>0$ for any possible $\mu$ if $1>\theta^{-1 / \varepsilon}(\varepsilon-1) /(\varepsilon-1+\gamma)$, which is the case for any $\gamma \in(0,1)$, according to (32). Recall that $\Gamma(\theta, \gamma)=0$ requires $\theta^{-1 / \varepsilon}<(\varepsilon-1+\gamma) /(\varepsilon-1)$ if $\gamma \in(0,1)$. For $\gamma=0, \Gamma(\theta, \gamma)=0$ implies $\theta=1$ and therefore $u=0$. This is the benchmark case of a perfectly competitive labor market.
} 
and in Footnote 7. The output of the homogeneous good is ceteris paribus decreasing in the share of multinational firms. All other things being equal, a higher $\mu$ is associated with higher fixed input requirements for setting up production facilities and therefore leaves a lower amount of capital for production in the homogeneous goods industry.

Using $Y=(1-\alpha) E$, we can show that income $E$ is given by

$$
E=\frac{1}{(1-\alpha)}(\bar{K}-(1+\mu(\rho-1)) N f) \text {. }
$$

Then, revenues of multinational firms can be determined from $\alpha E=2\left(m p_{m} x_{m}+(N-m) p_{n} x_{n}\right)=$ $p_{m} x_{m} 2 N\left(\mu+(1-\mu) \theta^{1-1 / \varepsilon}\right)$ jointly with $(39)$ :

$$
p_{m} x_{m}=\frac{\alpha}{(1-\alpha)} \frac{\bar{K}-(1+\mu(\rho-1)) N f}{2 N\left(\mu+(1-\mu) \theta^{1-1 / \varepsilon}\right)} .
$$

It is noteworthy that revenues are not directly related to the unemployment rate. The reason for this is that, for a given $\mu$, changes in $u$ do not exhibit an impact on aggregate income. See (39) and our discussion in section 2. Substituting (37) into (40) and using (6), we obtain

$$
w_{m}=\frac{\alpha(\varepsilon-1)}{(1-\alpha) \varepsilon} \frac{(\bar{K}-(1+\mu(\rho-1)) N f)}{(1-u) \bar{L}} \frac{\mu+(1-\mu) \theta}{\mu+(1-\mu) \theta^{1-1 / \varepsilon}}
$$

for the wage rate paid by a multinational enterprise. The respective factor costs of exporters are given by $w_{n}=w_{m} \theta^{-1 / \varepsilon}$. Finally, the average return to labor is

$$
\tilde{w}=\frac{\alpha(\varepsilon-1)}{(1-\alpha) \varepsilon} \frac{(\bar{K}-(1+\mu(\rho-1)) N f)}{(1-u) \bar{L}}
$$

according to (34) and (41). For a given $\mu$, the average wage is positively related to the unemployment rate. This confirms the respective insight under autarky. A higher share of multinational firms reduces the average wage rate, as MNEs pay lower wages.

All of these results have been derived under the assumption that both types of firms coexist and that the share of multinational enterprises $\mu \in(0,1)$ is exogenously given. It is now time to endogenize firm structure variable $\mu$. For this purpose, we determine the profits of exporters and multinational producers. According to (3), (6), (25) and (40), profits of a multinational firm are given by

$$
\pi_{m}=\zeta \frac{\bar{K}-(1+\mu(\rho-1)) N f}{N\left(\mu+(1-\mu) \theta^{1-1 / \varepsilon}\right)}-\rho f
$$

where $\zeta \equiv \frac{1}{\varepsilon} \frac{\alpha}{(1-\alpha)}$. The respective profits of exporting firms can be calculated using $p_{n} x_{n}=$ 
$p_{m} x_{m} \theta^{1-1 / \varepsilon}:$

$$
\pi_{n}=\theta^{1-1 / \varepsilon} \zeta \frac{\bar{K}-(1+\mu(\rho-1)) N f}{N\left(\mu+(1-\mu) \theta^{1-1 / \varepsilon}\right)}-f
$$

Hence, a multinational firm accrues higher operative profits $\left(\theta^{1-1 / \varepsilon}<1\right)$ but at the same time has to bear higher fixed costs for setting up an additional production facility abroad $(\rho>1)$. For a firm's decision to service consumers in the foreign market as an exporter or through local production, the profit differential $\Pi \equiv \pi_{m}-\pi_{n}$ is important. By virtue of (43) and (44), we have

$$
\Pi(\mu)=\left(1-\theta^{1-1 / \varepsilon}\right) \zeta \frac{\bar{K}-(1+\mu(\rho-1)) N f}{N\left(\mu+(1-\mu) \theta^{1-1 / \varepsilon}\right)}+(1-\rho) f .
$$

A firm serves the foreign market as a multinational firm if $\Pi>0$ and as an exporting firm if $\Pi<0$. In the case of $\Pi=0$, producers are indifferent between the two modes of foreign market penetration. The most important features and implications of the profit differential in (45) are summarized in lemma 2 :

Lemma 2 Consider $\theta \in(0,1]$. Then, the profit differential $\Pi(\mu)$ is decreasing in $\mu$. If $\Pi(0) \leq$ 0 , then $\mu=0$. If $\Pi(1) \geq 0$, then $\mu=1$. If $\Pi(0)>0>\Pi(1)$, then $\mu \in(0,1)$.

Proof. Differentiating (45) with respect to $\mu$ yields

$$
\frac{d \Pi}{d \mu}=[(1-\rho) f-\Pi(\mu)]\left[\frac{(\rho-1) N f}{(\bar{K}-(1+\mu(\rho-1)) N f)}+\frac{\left(1-\theta^{1-1 / \varepsilon}\right)}{\left(\mu+(1-\mu) \theta^{1-1 / \varepsilon}\right)}\right],
$$

which is clearly negative, if $\theta \in(0,1)$. And it is zero if $\theta=1$. The other results in lemma 2 are a direct consequence of the definition of $\Pi$ and the sign of $\partial \Pi / \partial \mu$.

If $\Pi(0)<0$ or $\Pi(1)>0$, the equilibrium is characterized by a corner solution where exporting firms and multinational producers do not coexist and marginal changes in $\Pi$ do not exhibit an impact on the distribution of firms. In contrast, $\Pi(0)>0>\Pi(1)$ gives rise to coexistence of exporters and multinationals. In this case, there exists a unique and stable interior solution and the share of multinational firms is determined by condition $\Pi(\mu)=0$ :

$$
\mu^{\prime}=\frac{1}{(\zeta+1)}\left[\zeta \frac{(\bar{K}-N f)}{(\rho-1) N f}-\frac{\theta^{1-1 / \varepsilon}}{\left(1-\theta^{1-1 / \varepsilon}\right)}\right]
$$

(Again, a prime refers to a "short run" variable for given entry and exit decisions of firms.) To obtain explicit solutions for the endogenous variables, we can substitute the equilibrium value of $\mu$ into (36)-(39), (41) and (42). This completes the characterization of the short-run equilibrium.

The endogenous determination of how production is organized in a setting with trade unions gives rise to a novel mechanism through which globalization effects may work. This warrants a 
detailed discussion of the comparative static effects on the firm pattern variable $\mu$. Thereby, we focus on a parameter domain with ${ }^{15} \Pi(0)>0>\Pi(1)$ and summarize our findings in proposition 1:

Proposition 1 Consider $\Pi(0)>0>\Pi(1)$. Then, the share of multinational firms is increasing in the supply of capital $\bar{K}$ and decreasing in the fixed cost components $f, \rho$, and the mass of competitors N. A marginal increase in $\gamma$ exhibits a positive impact on $\mu^{\prime}$ if $\gamma<\gamma^{*}$ and a negative one if $\gamma>\gamma^{*}$. Finally, changes in endowment parameter $\bar{L}$ or replacement ratio parameter $\beta$ do not affect firm structure variable $\mu^{\prime}$.

Proof. If $\Pi(0)>0>\Pi(1)$, the following partial derivatives can be calculated, according to (46): $\frac{\partial \mu^{\prime}}{\partial \bar{K}}=\frac{\zeta}{(\zeta+1)} \frac{1}{(\rho-1) N f}>0, \frac{\partial \mu^{\prime}}{\partial \rho}=-\frac{\zeta}{(\zeta+1)} \frac{(\bar{K}-N f)}{(\rho-1)^{2} N f}<0, \frac{\partial \mu^{\prime}}{\partial f}=-\frac{\zeta}{(\zeta+1)} \frac{\bar{K}}{(\rho-1) N f^{2}}<0$, $\frac{\partial \mu^{\prime}}{\partial N}=-\frac{\zeta}{(\zeta+1)} \frac{\bar{K}}{(\rho-1) f N^{2}}<0, \frac{\partial \mu^{\prime}}{\partial \theta}=-\frac{1}{(\zeta+1)} \frac{(1-1 / \varepsilon) \theta^{-1 / \varepsilon}}{\left(1-\theta^{1-1 / \varepsilon}\right)^{2}}<0, \frac{\partial \mu^{\prime}}{\partial \bar{L}}=0, \frac{\partial \mu^{\prime}}{\partial \beta}=0$. Moreover, using $\frac{\partial \mu^{\prime}}{\partial \theta}<0$ together with lemma 1 , we obtain $\frac{\partial \mu^{\prime}}{\partial \theta} \frac{d \theta}{d \gamma}>0$ if $\gamma<\gamma^{*}$ and $\frac{\partial \mu^{\prime}}{\partial \theta} \frac{d \theta}{d \gamma}<0$ if $\gamma>\gamma^{*}$. This completes the proof of proposition 1 .

A higher $\bar{K}$ induces higher demand for differentiated goods and renders multinational production more attractive (as the fixed cost differential becomes less important). A decline in $\rho$ or $f$ reduces the fixed cost differential $(\rho-1) f$ and leads to a higher share of MNEs $\mu^{\prime}$. A higher mass of competitors $N$ reduces output per individual firm $x_{i}(i=n, m)$, according to (37). This makes it more difficult for MNEs to finance the additional amount of fixed costs that is required for setting up a second production facility. Thus, $\mu^{\prime}$ delines in $N$. All of these effects are not new and would just as well arise in a standard international trade model where multinational activities are based on the traditional proximity-concentration trade-off.

The new mechanisms that this analysis focuses on are related to labor market imperfections and to the determination of wages in Nash bargaining. Hence, the comparative static effects of $\beta, \bar{L}$ and $\gamma$ changes are of particular interest here. A change in the replacement ratio $\beta$ exhibits no effect on firm structure variable $\mu^{\prime}$ (as long as $\beta<(\varepsilon-1) /(\varepsilon-1+\gamma)$ prevails). A higher $\beta$ raises wage costs $w_{j}, j=m, n$, according to (41). This leads to a proportional increase in price $p_{j}$ because of the constant markup rule. For a given output level, this raises revenues. But firm scale declines, according to (37). This counteracts and exactly offsets the aforementioned positive revenue effect, rendering operative profits independent of $\beta$, according to (43) and (44). An increase in $\bar{L}$ reduces the wage rate determined in the Nash bargain, but at the same time leads to an increase in firm scale, according to (37) and (41). Again, these counteracting effects cancel out, so that operative profis remain unaffected by changes in $\bar{L}$.

\footnotetext{
${ }^{15}$ Recall that marginal changes in the exogenous variables do not exhibit any impact on $\mu$, if either $\Pi(0)<0$ or $\Pi(1)>0$.
} 
Finally, the role of labor unions, and in particular the role of their bargaining power $\gamma$ for the equilibrium firm structure can be best described by recollecting the shape of $\tilde{\theta}(\gamma)$ as described in lemma 1. On the one hand, if $\gamma$ approaches zero, labor unions are weak and do not have a considerable impact on the outcome of the Nash bargain. As a consequence, the wage rate approaches its competitive value and no multinational firm survives due to the fixed cost disadvantage under two-plant production. On the other hand, if $\gamma$ approaches one, the bargaining position of firms becomes negligible, and their outside option plays no role in the determination of the bargaining outcome. Again, multinational enterprises are left with higher fixed costs, so that exporting is the more attractive alternative. These insights make clear that two plant production can only be an attractive way to escape high wage claims if the bargaining power of unions has an intermediate value. Otherwise, the fixed cost disadvantage renders multinational production unattractive. ${ }^{16}$

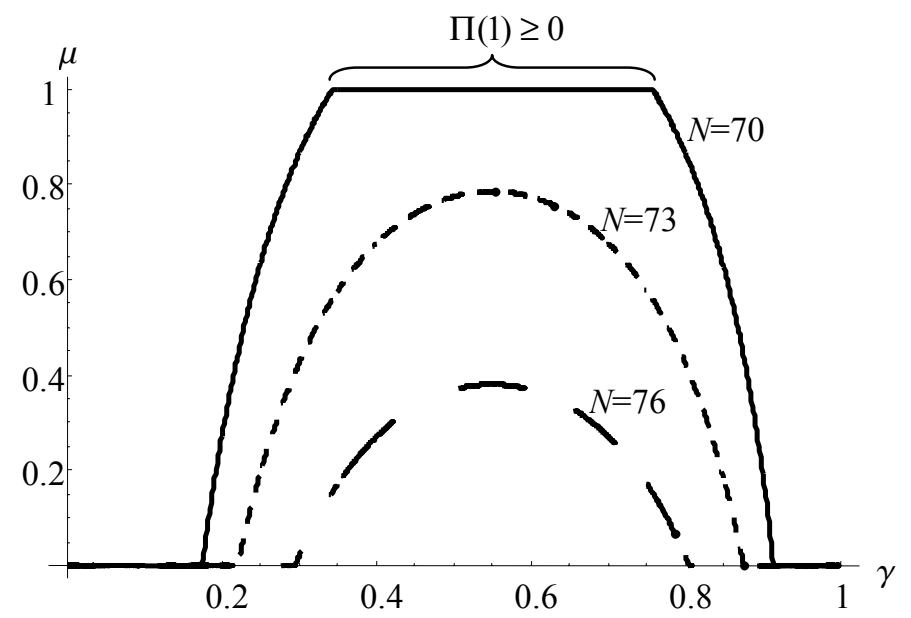

Figure 2: The impact of bargaining power parameter $\gamma$ on firm structure variable $\mu$

Figure 2 substantiates our finding that multinational production can only be attractive if the bargaining power of trade unions $\gamma$ is of intermediate size. Then, given that $\Pi(1)<0<\Pi(0)$, a marginal increase in $\gamma$ has a positive (negative) effect on the firm pattern variable $\mu^{\prime}$ if $\gamma<(>) \gamma^{*}$. Also the role of $N$ is illustrated in figure 2. A higher mass of competitors lowers firm scale, according to (37). This makes foreign investment less attractive. ${ }^{17}$

\footnotetext{
${ }^{16}$ This result qualifies the finding by Naylor and Santoni (2003) that the "equilibrium is less likely to be characterized by reciprocal foreign direct investment (...) the lower is the firm's bargaining power in either or both of the two markets" (pp. 10-11). Rather, by accounting for exports as an alternative option to penetrate the foreign market, we see that the impact of bargaining power $\gamma$ on firm structure variable $\mu$ is no longer monotonic. It is non-negative if unions are sufficiently weak and it is non-positive if unions are strong.

${ }^{17}$ To establish figure 2 , the following parameter values have been considered: $\alpha=0.75, \varepsilon=2, \rho=1.08$,
} 
With the determinants of the firm pattern at hand, we can study the impact of changes in the economic fundamentals on wages and unemployment, when the mode of foreign market penetration is endogenously adjusted. Our focus is still on the short-run equilibrium, while a detailed discussion of the long-run equilibrium with free entry is relegated to section 4 .

By virtue of (36) and (42), we can separate three channels of influence, through which economic fundamentals affect the labor market outcome: First, there is a direct effect, which refers to changes in $u$ and $\tilde{w}$ for given $\mu$ and $\theta$ levels. The respective comparative static results are in total analogy to those identified in the autarky scenario and, therefore, need no further discussion. ${ }^{18}$ Second, there is an indirect effect working through adjustments in firm structure variable $\mu$. The comparative static effects on $\mu^{\prime}$ are summarized in proposition 1. Equations (36) and (42) then allow us to identify the role of the firm pattern variable $\mu$ for the labor market outcome. A higher share of multinational enterprises reduces the average wage rate (and the relative factor return $\tilde{w} / r)$. The reason for this wage depressing effect is that multinational firms have a better bargaining position because of their outside option to produce abroad. Hence, they can negotiate lower wages than exporters and the average wage in the economy is falling in the share of multinational producers. However, a higher share of multinational firms also reduces the rate of unemployment. Because multinational firms pay lower wages, they produce at a larger scale. As a consequence, aggregate employment is increasing in the share of multinationals and unemployment is falling in $\mu .^{19}$ Third, there is an additional indirect effect working through changes in the output ratio $\theta$. Keeping $\varepsilon$ constant, $\theta$ changes can only be triggered by $\gamma$ variation. From lemma 1 we know that $d \theta / d \gamma<0$ if $\gamma<\gamma^{*}$, while $d \theta / d \gamma>0$ if $\gamma>\gamma^{*}$. Furthermore, it follows from (36) and (42) that, for a given $\mu>0$, a higher $\theta$ exhibits a positive impact on $u$ and $\tilde{w} .^{20}$ Together, these two effects determine the $\gamma$-implication working through the adjustment of $\theta$ for a given firm pattern $\mu$.

Proposition 2 The comparative static effects on unemployment rate $u$ and wage rate $\tilde{w}$ are $f=1000, \bar{L}=1000$ and $\bar{K}=100 \bar{L}$.

${ }^{18} \mathrm{An}$ exception is the $\rho$-effect, which has not been analyzed in section 2 . However, it follows immediately from (36) and (42) that, for a given $\mu$ and $\theta$, an increase in $\rho$ has no effect on the unemployment rate $u$ and reduces wage rate $\tilde{w}$ if $\mu>0$. (Compare the impact of fixed cost parameter $f$ as discussed in section 2).

${ }^{19}$ For a formal derivation of the $\mu$-effects, use $\frac{d u}{d \mu}=-\frac{1}{1-\beta} \frac{\varepsilon-1}{\varepsilon-1+\gamma} \theta\left(1-\theta^{1 / \varepsilon}\right)\left(\mu \theta^{1 / \varepsilon}+(1-\mu \theta)\right)^{-2}<0$. Moreover, note that $\frac{d \tilde{w}}{d \mu}=\frac{\partial \tilde{w}}{\partial \mu}+\frac{\partial \tilde{w}}{\partial u} \frac{d u}{d \mu}$. Then, $\frac{\partial \tilde{w}}{\partial \mu}=-\frac{\tilde{w}(\rho-1) N f}{K-(1+\mu(\rho-1)) f}<0, \frac{\partial \tilde{w}}{\partial u}=\frac{\tilde{w}}{(1-u)}>0$, together with $\frac{d u}{d \mu}<0$, guarantee $\frac{d \tilde{w}}{d \mu}<0$.

${ }^{20}$ Differentiating $u$ with respect to $\theta$ gives, according to (36),

$$
\frac{d u}{d \theta}=-\frac{1}{(1-\beta)} \frac{(\varepsilon-1)}{(\varepsilon-1+\gamma)} \frac{\mu\left\{(1-\mu)\left[\theta^{1 / \varepsilon}(\varepsilon-1) / \varepsilon-1\right]-(\mu / \varepsilon) \theta^{1 / \varepsilon-1}\right\}}{\left[\mu \theta^{1 / \varepsilon}+(1-\mu) \theta\right]} .
$$

Due to $\theta^{1 / \varepsilon}(\varepsilon-1) / \varepsilon<1, d u / d \theta$ is non-negative, and it is strictly positive if $\mu>0$. Furthermore, $d \tilde{w} / d \theta=$ $d \tilde{w} / d u \times d u / d \theta>0$ follows from (42). 
summarized in tables 1 and 2 below.

Proof. A detailed proof of the results in tables 1 and 2 has been relegated to a Supplement, which is available from the authros upon request.

Two results in tables 1 and 2 require further discussion. First, for a given firm pattern $\mu$, an increase in $N, f$ or $\rho$ does not affect unemployment rate $u$ and leads to a lower wage rate $\tilde{w}$. But if the respective parameter changes trigger an adjustment in the firm pattern and lower $\mu$, the unemployment rate increases. In addition, the wage rate effect becomes ambiguous if $N$ or $f$ increases, while wages increase with $\rho$. Second, while a decline in the replacement ratio, i.e. a reduction of $\beta$, always leads to lower unemployment and lower wages, the consequences of changes in the bargaining power of unions are more complicated. On the one hand, there is a direct effect of a $\gamma$ reduction, which leads to a decline in both wages and unemployment. On the other hand, there are indirect effects, arising from changes in firm pattern variable $\mu$ and output ratio $\theta$. If unions are strong and $\gamma>\gamma^{*}$, the indirect effects reinforce the direct one and weakening unions becomes particularly effective in reducing the unemployment problem. Of course, this positive employment effect comes at the costs of lower wage payments to those who are employed, as $\tilde{w}$ declines. In contrast, if unions are already weak, i.e. if $\gamma<\gamma^{*}$, a further reduction of their bargaining power leads to counteracting effects. In this case, it cannot be ruled out that weakening unions may aggrevate the unemployment problem. ${ }^{21}$

Summing up, tables 1 and 2 show that both product and labor market characteristics are important determinants of how unemployment rates and wages adjust to econmic integration. The particular pattern of these adjustments also depends on whether incumbent producers change their mode of firm organization (from single-plant towards two-plant production). This should be taken into account by policy makers, when deciding upon economic integration or upon product and labor market reforms to stimulate employment in a global economy. However, a precise policy recommendation is beyond the scope of this paper, as countries are assumed to be identical in all respects. This precludes a rigorous analysis of reforms at a national level.

\section{The long-run equilibrium under openness}

In the long run, there are no barriers to entry or exit of firms and the mass of active producers adjusts until zero profits are realized. A stable long run equilibrium is therefore characterized

\footnotetext{
${ }^{21}$ The existence of such an effect has been verified in a numerical simulation exercise (with the respective results available from the authors upon request). Of course, if $\gamma$ becomes low enough multinational firms vanish (see figure 2). Then, only the direct effect survives and reducing the bargaining power of unions definitely reduces the unemployment rate. In the borderline case of $\gamma=0$, we end up with full employment and $u=0$.
} 

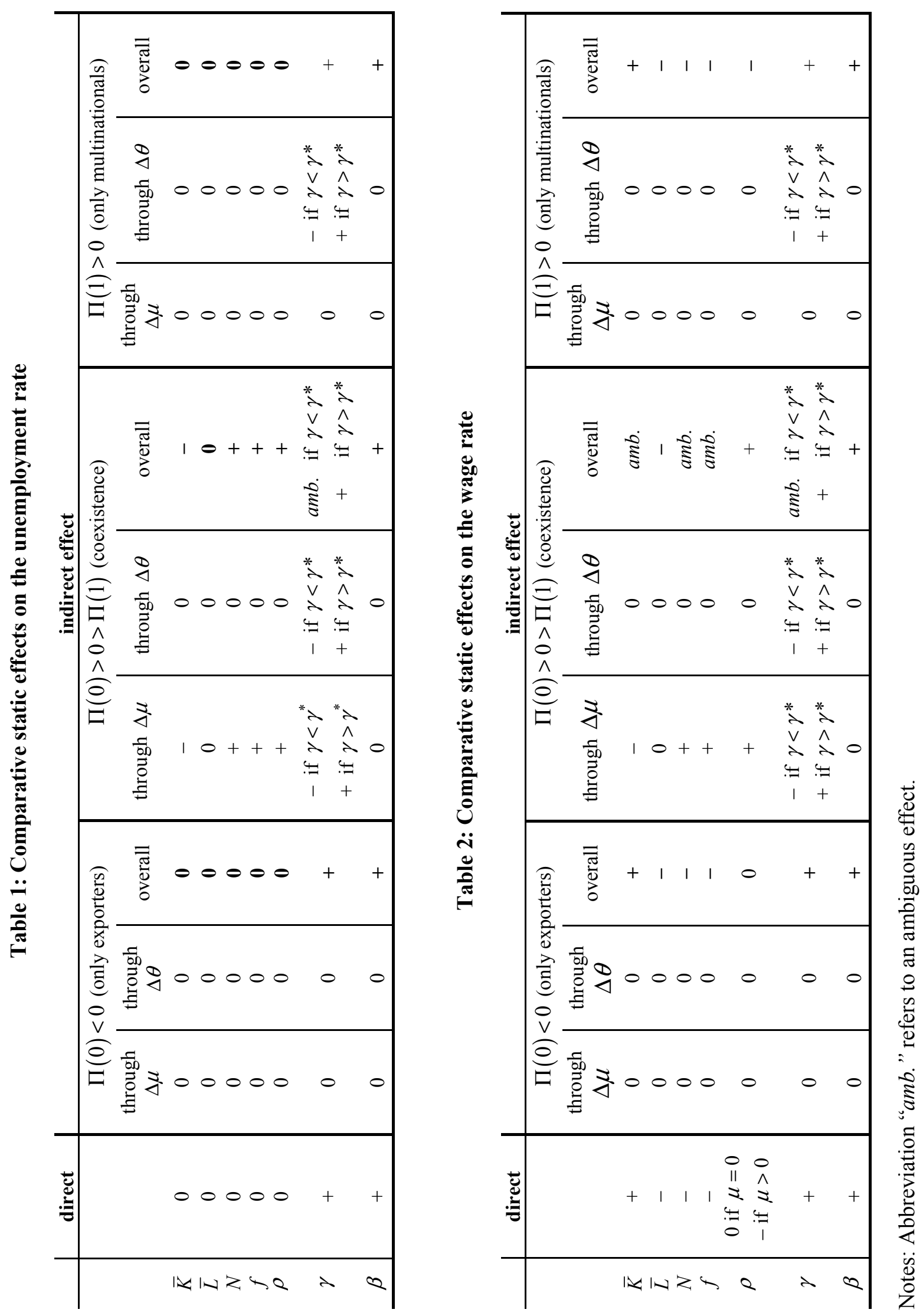
by

$$
\max \left\{\pi_{n}, \pi_{m}\right\}=0
$$

Three cases can be distinguished: First, we speak of a pure exporter equilibrium if $\pi_{n}=0$ and $\pi_{m}<0$. Second, $\pi_{n}<0$ and $\pi_{m}=0$ implies that exporting is unattractive and a pure multinational equilibrium arises. Finally, exporting firms and multinational producers can coexist if $\pi_{n}=\pi_{m}=0$.

From (43) and (44), we can derive the following relationship between the profits of exporters and MNEs:

$$
\pi_{m} \theta^{1-1 / \varepsilon}=\pi_{n}+\left(1-\theta^{1-1 / \varepsilon} \rho\right) f
$$

Proposition 3 The firm structure in the long-run equilibrium under openness depends on the relationship between $\theta^{1 / \varepsilon-1}$ and $\rho$. While $\theta^{1 / \varepsilon-1}<\rho$ gives rise to a pure exporter $(E X P)$ equilibrium, $\theta^{1 / \varepsilon-1}>\rho$ implies a pure multinational (MNE) equilibrium. Finally, coexistence of exporters and multinational producers is only possible in the borderline case of $\theta^{1 / \varepsilon-1}=\rho$.

Proof. From (48) we obtain

$$
\left.\pi_{m}\right|_{\pi_{n}=0}=\left.\left(\theta^{1 / \varepsilon-1}-\rho\right) f \quad \pi_{n}\right|_{\pi_{m}=0}=\left(\rho-\theta^{1 / \varepsilon-1}\right) \theta^{1-1 / \varepsilon} f
$$

which establishes the results in proposition 3.

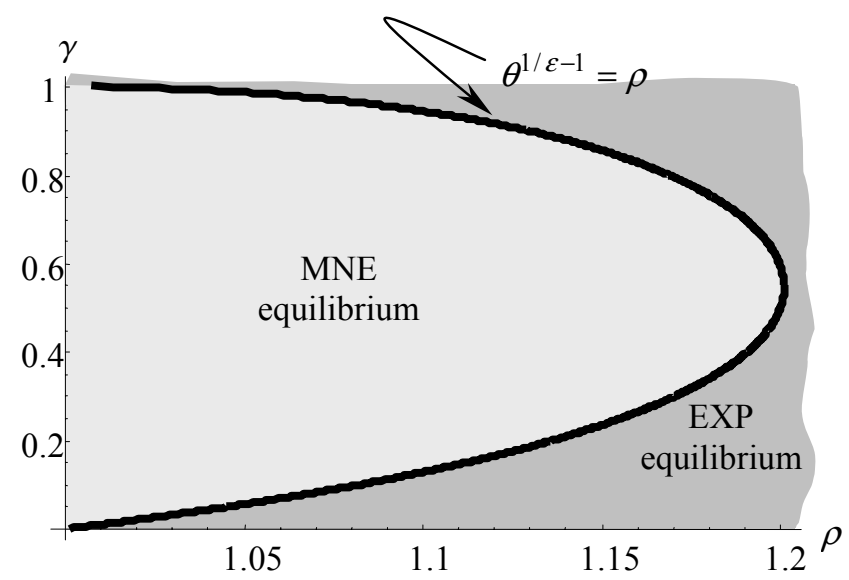

Figure 3: Long-run MNE- and EXP-equilibria

The economic intuition behind the results in proposition 3 becomes obvious, when noting (i) that $\theta^{1 / \varepsilon-1}$ gives the revenue differential in favor of multinationals and (ii) that $\rho$ measures the fixed cost disadvantage of two-plant production in relative terms. If the advantage of twoplant activities due to higher revenues dominates the disadvantage from higher fixed costs, it is 
optimal for producers to choose an MNE strategy, while exporting is the more attractive choice if $\rho$ is high and $\theta^{1 / \varepsilon-1}$ is sufficiently low. Finally, if $\rho=\theta^{1 / \varepsilon-1}$, both types of firms can coexist, with the equilibrium firm structure $\mu$ being undetermined.

The revenue differential itself depends on the bargaining power of unions $(\gamma)$. Thus, the long run mode of foreign market penetration is ultimately determined by two factors: $\gamma$ and $\rho$. This result is substantiated by figure 3 , where the $\rho=\theta^{1 / \varepsilon-1}$-locus separates the parameter domain which leads to a pure MNE-equilibrium from the parameter domain for which a pure EXP-equilibrium arises in the long run. ${ }^{22}$

In a next step, we can solve for the key endogenous variables in the long-run equilibrium. They are conditional on the firm structure $(\mu=0$ or $\mu=1)$, as made clear in the following table: ${ }^{23}$

\section{Table 3: The long-run equilibrium under openness}

\begin{tabular}{l|l|l||} 
& \multicolumn{1}{|c|}{$\begin{array}{c}\text { EXP-equilibrium } \\
\left(\rho>\theta^{1 / \varepsilon-1} \Rightarrow \mu=0\right)\end{array}$} & $\begin{array}{c}\text { MNE-equilibrium } \\
\left(\rho<\theta^{1 / \varepsilon-1} \Rightarrow \mu=1\right)\end{array}$ \\
\hline number of firms & $N^{\prime \prime}=\frac{\alpha}{\alpha+\varepsilon(1-\alpha)} \frac{\bar{K}}{f}$ & $N^{\prime \prime}=\frac{\alpha}{\alpha+\varepsilon(1-\alpha)} \frac{\bar{K}}{\rho f}$ \\
unemployment rate & $u^{\prime \prime}=\frac{1}{(1-\beta)}\left(1-\frac{\varepsilon-1}{\varepsilon-1+\gamma}\right)$ & $u^{\prime \prime}=\frac{1}{(1-\beta)}\left(1-\frac{\varepsilon-1}{\varepsilon-1+\gamma} \theta^{-1 / \varepsilon}\right)$ \\
output per firm & $x_{n}^{\prime \prime}=\frac{\alpha+\varepsilon(1-\alpha)}{\alpha} \frac{\left(1-u^{\prime \prime}\right) f \bar{L}}{\bar{K}}$ & $x_{m}^{\prime \prime}=\frac{\alpha+\varepsilon(1-\alpha)}{\alpha} \frac{\left(1-u^{\prime \prime}\right) \rho f \bar{L}}{2 \bar{K}}$ \\
wage rate & $w_{n}^{\prime \prime}=\frac{\alpha(\varepsilon-1)}{\alpha+\varepsilon(1-\alpha)} \frac{\bar{K}}{\left(1-u^{\prime \prime}\right) \bar{L}}$ & $w_{m}^{\prime \prime}=\frac{\alpha(\varepsilon-1)}{\alpha+\varepsilon(1-\alpha)} \frac{\bar{K}}{\left(1-u^{\prime \prime}\right) \bar{L}}$ \\
aggregate income & $E^{\prime \prime}=\frac{\varepsilon}{\alpha+\varepsilon(1-\alpha)} \bar{K}$ & $E^{\prime \prime}=\frac{\varepsilon}{\alpha+\varepsilon(1-\alpha)} \bar{K}$ \\
\hline \hline
\end{tabular}

A comparison of the first and the second column in table 3 shows that the mass of producers is lower in the MNE-equilibrium, because multinational production requires higher fixed costs. Also wages are lower in the MNE-equilibrium. This is intuitive, as we know from section 3 that multinational producers pay a lower factor return. However, the higher wage income of workers in the exporter equilibrium comes at the cost of a higher unemployment rate. Again, this is consistent with our insights in the last section.

In the long run, fixed cost parameter $f$ has no impact on wages or the unemployment rate. The same holds for $\rho$ as long as the firm pattern variable $\mu$ is unchanged. However, a sufficiently pronounced increase in $\rho$ may trigger a switch from an MNE-equilibrium to an EXP-equilibrium,

\footnotetext{
${ }^{22}$ To establish figure $3, \varepsilon=2$ has been considered.

${ }^{23}$ Use (43) and (44), to calculate the mass of producers for $\mu=0$ and $\mu=1$, according to the zero profit conditions. This gives the two values of $N^{\prime \prime}$ in the first row of table 3. Moreover, use $\mu=0$ and $\mu=1$, respectively, in (36) to obtain the equilibrium unemployment rate $u^{\prime \prime}$. The values of $q_{n}^{\prime \prime}, w_{n}^{\prime \prime}$ and $E^{\prime \prime}$ in the left column of the table follow from substituting $\mu=0$ and the respective $N^{\prime \prime}$-value in (37), (39) and (42). In analogy, the values of $q_{m}^{\prime \prime}, w_{m}^{\prime \prime}$ and $E^{\prime \prime}$ in the right column of the table follow from substituting $\mu=1$ and the respective $N^{\prime \prime}$-value in (37), (39) and (42).
} 
with severe wage and unemployment implications. The effects of $f$ and $\rho$ point to an important difference between the short and the long run. In the short run, fixed cost variation exhibits a direct effect on $\tilde{w}$ and $u$ (even for a constant $\mu$ ). An increase in $f$ and $\rho$ (if $\mu>0$ ) lowers aggregate income and profits. Since the factor return to labor is linked to profits through wage bargaining, $\tilde{w}$ declines for a given mass of producers and a constant $\mu$. This effect is counteracted by firm exit in the long run. Firm exit raises profits of incumbent producers and therefore augments wages (for a given type of equilibrium, i.e. a given $\mu$ ). In sum, the two opposing effects cancel out in the long run, so that the direct effect of $f$ and $\rho$ on the wage rate vanishes.

The impact of $\beta$ and $\gamma$ variation on wages and unemployment in the long run follows immediately from proposition 1 and tables 1 and 2 . A higher replacement ratio $\beta$ aggravates the unemployment problem and leads to higher wages. The same holds true for a higher bargaining power of unions $\gamma$, as long as the type of the long-run equilibrium remains unchanged. However, if a $\gamma$ variation triggers a change in the type of long-run equilibium (from MNE to EXP, or vice versa), a monotonic relatinship between $\gamma$ and unemployment rate $u$ is no longer guaranteed. A $\gamma$ increase, that leads from an MNE-equilibrium to an EXP-equilibrium definitely has adverse unemployment effects, while a $\gamma$ reduction that leads from an MNE-equilibrium to an EXPequilibrium may increase or reduce the employment level. The unemployment and the wage effects go into the same direction, according to table 3 .

\section{From autarky to economic integration: A tale of globalization}

In sections 2-4 we have analyzed the role of wage bargaining under autarky and under openness. In this section, we use our theoretical insights to draw a comprehensive picture of how economic integration affects wages and unemployment if labor markets are unionized. Starting point is a long-run autarky equilibrium, as characterized in section 2 . After the fall of trade and investment barriers from infinity to zero, the two economies find themselves in a short-run environment, in which firms can choose their mode of foreign market penetration but producers do not adjust their entry/exit decisions. In the long run, market forces reestablish a zero-profit equilibrium.

Table 4 summarizes the possible scenarios. ${ }^{24}$ If $\rho>\theta^{1 / \varepsilon-1}$ gives rise to a pure exporter equilibrium in the long run, exporting will also be the more attractive mode of foreign market penetration in the short run. Indeed, if a long-run autarky equilibrium is the starting point, it follows from (18) and (44) that $\pi_{n}=0$ if $\mu=0$. Then, (48) implies $\left.\pi_{m}\right|_{\pi_{n}=0}<0$ if $\mu=0$ and $\rho>\theta^{1 / \varepsilon-1}$ (see proposition 3 ). In this case, labor market variables remain constant during the process of globalization: $u_{a}=u^{\prime}=u^{\prime \prime}=0.1$ and $w_{a}^{\prime \prime}=\tilde{w}^{\prime}=\tilde{w}^{\prime \prime}=7.11$. And we can formulate

\footnotetext{
${ }^{24}$ The following parameter values have been used to establish the results in table $4: \alpha=0.75, \varepsilon=4, \beta=0.6$, $\gamma=0.12, f=1000, \bar{L}=1000, \bar{K}=5 \bar{L}$.
} 
Table 4: Wage and unemployment effects of globalization

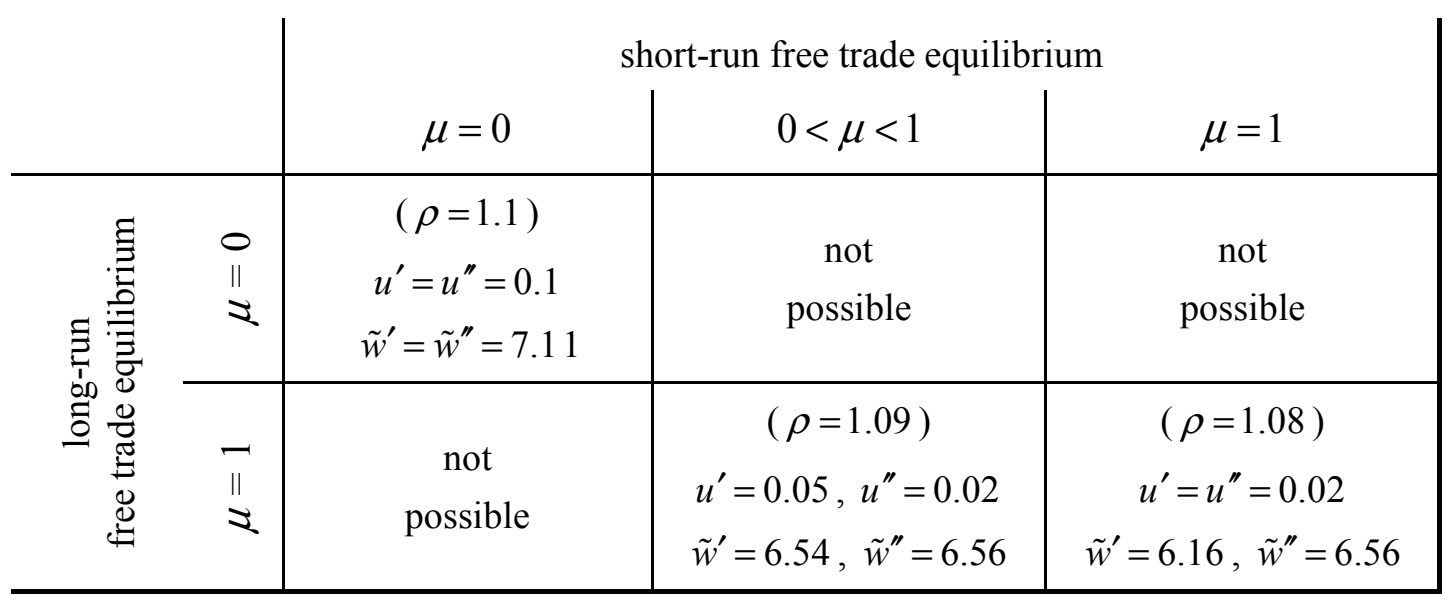

the following conclusion: If the fixed cost disadvantage of two-plant production is sufficiently high, both wages and unemployment remain unaffected by economic integration.

Things are different if $\rho<\theta^{1 / \varepsilon-1}$. In this case, two-plant production becomes attractive after the fall in trade and investment barriers. If $\rho$ is of intermediate size, there is coexistence of exporters and MNEs in the short run, while a pure MNE equilibrium is the outcome if $\rho$ is close to one and the additional fixed cost for setting up a foreign production facility, $(\rho-1) f$, are negligible. In the long run, when firms adjust their entry/exit decisions and a zero-profit free trade equilibrium is realized, local affiliate production is the preferred mode of foreign market penetration (given that $\rho<\theta^{1 / \varepsilon-1}$ ). Whenever economic integration leads to evolution of multinational producers, it is a cure for high unemployment rates.

The finding that economic integration is a stimulus for employment may be surprising at a first glance. Of course, going multinational lowers domestic production and raises unemployment, all other things equal. This effect has been emphasized by Lommerud, Meland and Sørgard (2003) who conclude that "strong unions and trade liberalisation do not sit well together" (p. 799). However, our focus is on economic integration between two fully identical countries. This gives rise to two-way investment flows, with the positive effect of incoming investment dominating the negative effect of outgoing investment. Hence, economic integration between similar economies is beneficial if it leads to the evolution of multinational firms. The reduction in the unemployment rate comes at the cost of lower wage payments. This explains a conflict between employed and unemployed workers, when economic integration is at the political agenda. While the unemployed should advocate the decline in trade and investment barriers, those who have a 
job should be more sceptical. ${ }^{25}$

The results in table 4 also contribute to the recent discussion on the evolution of withingroup wage inequality. ${ }^{26}$ While the existing literature primarily points to the role of technological progress and/or organizational change for explaining this phenomenon ${ }^{27}$, our model shows that multinational activities can explain the time pattern in the evolution of within-group wage inequality. ${ }^{28}$ However, as indicated by table 4, within-group wage inequality may be a temporary phenomenon, which vanishes when market forces reestablish a zero-profit equilibrium.

\section{Concluding remarks}

This paper has shed light on the role of trade union activities for the decision of firms to penetrate a foreign market through exports or through production of a local subsidiary. As outlined above, a second production facility abroad improves the outside option of a multinational enterprise in its wage bargain with a domestic union. This leads to lower wage payments (as compared to exporters) and renders foreign investment more attractive. In addition, it has been shown how the endogeneous change in the firm pattern affects the labor market adjustments to economic integration. As multinational enterprises negotiate lower wages, a decline in the ratio of MNEs relative to exporters ceteris paribus leads to higher wage payments. However, this comes at the cost of a higher unemployment rate, as multinational firms produce at a higher scale than exporters.

Throughout our analysis, we have rigorously distinguished between short-run and long-run consequences to separate temporary firm pattern effects from permanent firm entry/exit implications. In particular, we have shown that within-group wage inequality can be explained by the evolution of multinational enterprises after the fall in trade and investment barriers. However, our results indicate that within-group wage inequality is a temporary phenomenon, which is eliminated in the long run, when market forces reestablish a zero-profit equilibrium.

Finally, this paper also provides insights into the role of policy variables, like the bargaining power of unions or the replacement ratio for the unemployed. While a reduction in the replacement ratio has the expected positive employment effect, the consequences of a reduction in the

\footnotetext{
${ }^{25}$ Our simple framework neglects any intertemporal aspects. In a dynamic setting with an exogenous quit rate (cf. Layard and Nickell, 1990; Beissinger and Egger, 2004), a lower unemployment rate is associated with a higher reemployment probability, which raises the expected lifetime income of any worker. Such a positive effect is eliminated in our static analysis.

${ }^{26}$ Recall that all workers are assumed to be fully identical in all their individual characterisitics.

${ }^{27}$ See Egger and Grossmann ( 2005) for an overview of the relevant literature

${ }^{28}$ Interestingly, the evolution and increase of within-group wage inequality was almost parallel to the surge of foreign direct investment and multinational activities in the last thirty years. Furthermore, the increase in within-group wage inequality was - in contrast to between-group wage inequality - not confined to the US (Katz and Autor, 1999; Fitzenberger, Hujer, McCurdy and Schnabel, 2001; Barth, Lucifora and Tsakloglou, 2005).
} 
bargaining power of unions are less clear if firms adjust their mode of foreign market penetration. Hence, governments should be cautious when changing the bargaining position of unions (e.g., through legislative interventions). Of course, these policy recommendations are rather vague and they are derived under the caveat that economic integration of two fully identical economies has been studied. To draw stronger conclusions, clearly requires a less restrictive framework, in which asymmetries in the economic and political fundamentals of countries are allowed for. Such an extension is beyond the scope of the present paper, but it may be a worthwhile task for a future project.

\section{Appendix}

\section{The wage-setting curve under autarky}

To solve the maximization problem in (7), we can use the following Lagrangian function

$$
\mathcal{L}(w(i), x(i), \lambda)=\{x(i)[w(i)-\bar{w}]\}^{\gamma}\{\pi(i)-\bar{\pi}\}^{1-\gamma}-\lambda d \pi(i) / d x(i)
$$

Substituting (4), the three first-order conditions for the maximization problem are given by

$$
\begin{aligned}
\frac{\partial \mathcal{L}}{\partial w(i)} & =\Omega\left[\frac{\gamma}{w(i)-\bar{w}}-\frac{(1-\gamma) x(i)}{\pi(i)-\bar{\pi}}\right]+\lambda=0, \\
\frac{\partial \mathcal{L}}{\partial x(i)} & =\Omega\left[\frac{\gamma}{x(i)}+\frac{(1-\gamma) d \pi(i) / d x(i)}{\pi(i)-\bar{\pi}}\right]-\lambda \frac{d^{2} \pi(i)}{d x(i)^{2}}=0, \\
\frac{\partial \mathcal{L}}{\partial \lambda} & =\frac{d \pi(i)}{d x(i)}=0 .
\end{aligned}
$$

We can now use (4) and (5) to calculate

$$
\begin{aligned}
\pi(i)-\bar{\pi}(i) & =\left(\frac{\alpha E}{P}\right)^{1 / \varepsilon} x(i)^{1-1 / \varepsilon}-w(i) x(i) \\
& =\frac{1}{\varepsilon}\left(\frac{\alpha E}{P}\right)^{1 / \varepsilon} x(i)^{1-1 / \varepsilon} \\
\frac{d^{2} \pi(i)}{d x(i)^{2}} & =-\frac{1}{\varepsilon}\left(1-\frac{1}{\varepsilon}\right)\left(\frac{\alpha E}{P}\right)^{1 / \varepsilon} x(i)^{-1-1 / \varepsilon}
\end{aligned}
$$

Substituting (A5) and (A6) into (A2)-(A4), the following expression can be derived from the three first-order conditions:

$$
\frac{1}{w(i)-\bar{w}}=\left[\frac{\varepsilon}{\varepsilon-1}+\frac{1-\gamma}{\gamma}\right]\left[\frac{1}{\varepsilon}\left(\frac{\alpha E}{P}\right)^{1 / \varepsilon} x(i)^{-1 / \varepsilon}\right]^{-1} .
$$


Rearranging terms gives the wage-setting curve in (8). $Q E D$

\section{The wage-setting curve under exporting}

Under openness, we have to use country indices to distinguish the local from the foreign market. Then, to solve the maximization problem of a firm-union bargaining pair in country $j \neq k$, we can write down the following Lagrangian function

$$
\begin{aligned}
\mathcal{L}\left(w_{n}^{j}(i), x_{n}^{j}(i), x_{n}^{k}(i), \lambda^{j}, \lambda^{k}\right)=\left\{\left[x_{n}^{j}(i)+x_{n}^{k}(i)\right]\right. & {\left.\left[w_{n}^{j}(i)-\bar{w}^{j}\right]\right\}^{\gamma}\left\{\pi_{n}^{j}(i)-\bar{\pi}_{n}\right\}^{1-\gamma} } \\
& -\lambda^{j} d \pi_{n}^{j}(i) / d x_{n}^{j}(i)-\lambda^{k} d \pi_{n}^{j}(i) / d x_{n}^{k}(i) .
\end{aligned}
$$

Then, the five first-order conditions for the maximization problem are given by

$$
\begin{aligned}
\frac{\partial \mathcal{L}}{\partial w_{n}^{j}(i)} & =\Omega^{j}\left[\frac{\gamma}{w_{n}^{j}(i)-\bar{w}^{j}}-\frac{(1-\gamma)\left[x_{n}^{j}(i)+x_{n}^{k}(i)\right]}{\pi_{n}^{j}(i)-\bar{\pi}_{n}}\right]+\lambda^{j}+\lambda^{k}=0, \\
\frac{\partial \mathcal{L}}{\partial x_{n}^{j}(i)} & =\Omega^{j}\left[\frac{\gamma}{x_{n}^{j}(i)+x_{n}^{k}(i)}+\frac{(1-\gamma) d \pi_{n}^{j}(i) / d x_{n}^{j}(i)}{\pi_{n}^{j}(i)-\bar{\pi}_{n}}\right]-\lambda^{j} \frac{d^{2} \pi_{n}^{j}(i)}{d x_{n}^{j}(i)^{2}}=0, \\
\frac{\partial \mathcal{L}}{\partial x_{n}^{k}(i)} & =\Omega^{j}\left[\frac{\gamma}{x_{n}^{j}(i)+x_{n}^{k}(i)}+\frac{(1-\gamma) d \pi_{n}^{k}(i) / d x_{n}^{k}(i)}{\pi_{n}^{j}(i)-\bar{\pi}_{n}}\right]-\lambda^{k} \frac{d^{2} \pi_{n}^{j}(i)}{d x_{n}^{k}(i)^{2}}=0, \\
\frac{\partial \mathcal{L}}{\partial \lambda^{j}} & =\frac{d \pi_{n}^{j}(i)}{d x_{n}^{j}(i)}=0, \quad \frac{\partial \mathcal{L}}{\partial \lambda^{k}}=\frac{d \pi_{n}^{j}(i)}{d x_{n}^{k}(i)}=0 .
\end{aligned}
$$

In the case of two symmetric countries and no transport costs, we can set $E^{j}=E^{k} \equiv E, P^{j}=$ $P^{k} \equiv P$ and $\lambda^{j}=\lambda^{k}$. This implies $x_{n}^{j}(i)=x_{n}^{k}(i)$ and $\pi_{n}^{j}(i)-\bar{\pi}_{n}=\pi_{n}^{j}(i)+f$. Then, accounting for (A5) and (A6), we can derive the following expression from the first-oder conditions in (A9)-(A12)

$$
\frac{1}{w_{n}^{j}(i)-\bar{w}_{n}^{j}}=\left[\frac{\varepsilon}{\varepsilon-1}+\frac{1-\gamma}{\gamma}\right]\left[\frac{1}{\varepsilon}\left(\frac{\alpha E}{P}\right)^{1 / \varepsilon} x^{j}(i)^{-1 / \varepsilon}\right]^{-1} .
$$

Rearranging terms, the wage-setting curve in (26) immediately follows. QED

\section{The wage-setting curve under multinational activity}

In the case of a multinational producer, the plant-union bargaining pair in country $j$ takes foreign wages and outside options $\bar{w}^{j}, \bar{\pi}_{m}^{j}$ as exogenously given. To solve the Nash problem for this case, we can write down the following Lagrangian function:

$$
\mathcal{L}\left(w_{m}^{j}(i), x_{m}^{j}(i), \lambda\right)=\left\{x_{m}^{j}(i)\left[w_{m}^{j}(i)-\bar{w}^{j}\right]\right\}^{\gamma}\left\{\pi_{m}^{j}(i)-\bar{\pi}_{m}^{j}\right\}^{1-\gamma}-\lambda d \pi_{m}^{j}(i) / d x_{m}^{j}(i)
$$


Substituting (25), the first-order conditions for the maximization problem under multinational production are given by $^{29}$

$$
\begin{aligned}
\frac{\partial \mathcal{L}}{\partial w_{m}^{j}(i)} & =\Omega^{j}\left[\frac{\gamma}{w_{m}^{j}(i)-\bar{w}^{j}}-\frac{(1-\gamma) x_{m}^{j}(i)}{\pi_{m}^{j}(i)-\bar{\pi}_{m}^{j}}\right]+\lambda=0, \\
\frac{\partial \mathcal{L}}{\partial x_{m}^{j}(i)} & =\Omega^{j}\left[\frac{\gamma}{x_{m}^{j}(i)}+\frac{(1-\gamma) d \pi_{m}^{j}(i) / d x_{m}^{j}(i)}{\pi_{m}^{j}(i)-\bar{\pi}_{m}^{j}}\right]-\lambda \frac{d^{2} \pi_{m}^{j}(i)}{d x_{m}^{j}(i)^{2}}=0, \\
\frac{\partial \mathcal{L}}{\partial \lambda} & =\frac{d \pi_{m}^{j}(i)}{d x_{m}^{j}(i)}=0 .
\end{aligned}
$$

Before we can explicitly solve for the wage-setting curve, we have to specify the outside option of the multinational producer in the Nash bargain. Under perfect foresight, the foreign delegates anticipate the bargaining outcome in $j$, in their own wage negotiations. The maximum attainable profits of the foreign plant, if an agreement in the domestic bargain is not reached, is therefore given by $\pi_{n}^{k}$. This implies $\bar{\pi}_{m}^{j}=\pi_{n}^{k}-(\rho-1) f$. In the case of symmetric countries, we can omit country indices, so that multinational firm $i$ 's contribution to the Nash product in country $j$ is given by

$$
\begin{aligned}
\pi_{m}(i)-\bar{\pi} & =2\left\{\left(\frac{\alpha E}{P}\right)^{1 / \varepsilon}\left[x_{m}(i)^{1-1 / \varepsilon}-x_{n}(i)^{1-1 / \varepsilon}\right]-w_{m}(i) x_{m}(i)+w_{n}(i) x_{n}(i)\right\} \\
& =\frac{2}{\varepsilon}\left(\frac{\alpha E}{P}\right)^{1 / \varepsilon}\left[x_{m}(i)^{1-1 / \varepsilon}-x_{n}(i)^{1-1 / \varepsilon}\right],
\end{aligned}
$$

according to (24) and (25). Denoting output shares by $\theta=x_{n} / x_{m}$ and substituting (A6) and (A18) into (A15)-(A17), we can derive the following expression

$$
\frac{1}{w_{m}(i)-\bar{w}}=\left[\frac{\varepsilon}{\varepsilon-1}+\frac{1-\gamma}{2 \gamma\left(1-\theta^{1-1 / \varepsilon}\right)}\right]\left[\frac{1}{\varepsilon}\left(\frac{\alpha E}{P}\right)^{1 / \varepsilon} x_{m}(i)^{-1 / \varepsilon}\right]^{-1}
$$

which ultimately determines the wage-setting curve in (27). $Q E D$

\section{Proof of lemma 1}

The proof is organized in three steps: In step (i), we show that $\Gamma(\theta, \gamma)=0$ determines a continuous and twice differentiable function $\tilde{\theta}(\gamma)$ on interval $[0,1)$, which has the following two properties: $\tilde{\theta}(0)=1$ and $\tilde{\theta}(\gamma) \in(0,1) \forall \gamma \in[0,1)$. In step (ii), we prove existence of $\lim _{\gamma \rightarrow 1} \tilde{\theta}(\gamma)$ and demonstrate that $\tilde{\theta}(\gamma) \rightarrow 1$ if $\gamma \rightarrow 1$. Finally, in step (iii), we confirm that $\tilde{\theta}(\gamma)$ has a unique

\footnotetext{
${ }^{29}$ Note the similarity to the first-order conditions under autarky.
} 
minimum at some $\gamma^{*} \in(0,1)$, so that $d \tilde{\theta}(\gamma) / d \gamma<0$ for any $\gamma \in\left[0, \gamma^{*}\right)$ and $d \tilde{\theta}(\gamma) / d \gamma>0$ for any $\gamma \in\left(\gamma^{*}, 1\right)$. Throughout the proof we consider $\varepsilon \geq 2$.

Step (i): First, setting $\gamma=0, \theta=1$ follows immediately from (32). Second, differentiating $\Gamma(\cdot)$ with respect to $\theta$, gives

$$
\Gamma_{\theta}(\theta, \gamma)=-\frac{2 \gamma \theta^{-1 / \varepsilon}(1-\gamma)(\varepsilon-1)^{2}}{\varepsilon\left[2 \varepsilon \gamma\left(1-\theta^{1-1 / \varepsilon}\right)+(1-\gamma)(\varepsilon-1)\right]^{2}}-\frac{\varepsilon-1}{\varepsilon(\varepsilon-1+\gamma)} \theta^{-1-1 / \varepsilon},
$$

which is negative for any $\gamma \in[0,1)$. Then, noting $\Gamma(0, \gamma)=\infty$ and $\Gamma(1, \gamma)=-\gamma /(\varepsilon-1+\gamma)$, it follows that, for any $\gamma \in[0,1), \Gamma(\theta, \gamma)=0$ has a unique solution in $\theta$ on interval $(0,1] .{ }^{30}$ Third, differentiating $\Gamma(\cdot)$ with respect to $\gamma$, we obtain

$$
\Gamma_{\gamma}(\theta, \gamma)=\frac{2(\varepsilon-1)\left(1-\theta^{1-1 / \varepsilon}\right)}{\left[2 \varepsilon \gamma\left(1-\theta^{1-1 / \varepsilon}\right)+(1-\gamma)(\varepsilon-1)\right]^{2}}-\frac{\varepsilon-1}{[\varepsilon-1+\gamma]^{2}} \theta^{-1 / \varepsilon} .
$$

Since $\Gamma_{\gamma}$ exists for any $\gamma \in[0,1)$ and $\theta \in(0,1]$, we can apply the implicit function theorem to (32). This gives a continuous and twice differentiable function $\tilde{\theta}(\gamma)$, with the following first and second derivatives:

$$
\begin{gathered}
\frac{d \tilde{\theta}(\gamma)}{d \gamma}=-\frac{\Gamma_{\gamma}(\cdot)}{\Gamma_{\theta}(\cdot)} \\
\frac{d^{2} \tilde{\theta}(\gamma)}{d \gamma^{2}}=-\frac{\left[\Gamma_{\gamma \gamma}+\Gamma_{\gamma \theta} d \tilde{\theta}(\gamma) / d \gamma\right]+\left[\Gamma_{\theta \gamma}+\Gamma_{\theta \theta} d \tilde{\theta}(\gamma) / d \gamma\right] d \tilde{\theta}(\gamma) / d \gamma}{\Gamma_{\theta}}
\end{gathered}
$$

Step (ii): The results in step (i) imply that there exists a unique $\theta^{*} \in[0,1)$, such that $\Gamma(\theta, \gamma)=0$ has a solution in $\gamma \in(0,1)$ if $\theta \in\left[\theta^{*}, 1\right)$, while it has no solution in $\gamma \in(0,1)$ if $\theta \in\left[0, \theta^{*}\right)$. Since evaluating $(32)$ at $\theta=0.5^{\varepsilon /(\varepsilon-1)}$ gives

$$
\Gamma\left(0.5^{\varepsilon /(\varepsilon-1)}, \gamma\right)=\frac{\varepsilon-1}{\varepsilon-1+\gamma}\left[0.5^{-1 /(\varepsilon-1)}-1\right]>0
$$

it follows from $\Gamma_{\theta}<0$ that $\theta^{*}>0.5^{\varepsilon /(\varepsilon-1)}$. This implies that

$$
\Gamma_{\gamma}(\theta, 0)=\frac{1}{\varepsilon-1}\left[2\left(1-\theta^{1-1 / \varepsilon}\right)-\theta^{-1 / \varepsilon}\right]<0
$$

holds for any $\theta \in\left[\theta^{*}, 1\right]$.

Next, we determine the sign of $\Gamma_{\gamma}(\theta, 1)$. Therefore, consider that $\Gamma(\theta, 0)=\theta^{-1 / \varepsilon}-1>0$ and

\footnotetext{
${ }^{30}$ Solutions with $\theta>1$ are not considered.
} 
$\Gamma(\theta, 1)=[(\varepsilon-1) / \varepsilon]\left(\theta^{-1 / \varepsilon}-1\right)>0$ for any $\theta \in(0,1)$. Noting further that, for any $\theta \in\left[\theta^{*}, 1\right)$, $\Gamma=0$ has a solution on interval $(0,1)$, it is straightforward that, for any relevant $\theta, \Gamma(\theta, \gamma)$ has a local minimum at some $\gamma^{e}(\theta) \in(0,1)$, with $\Gamma_{\gamma}\left(\theta, \gamma^{e}(\theta)\right)=0$ and

$$
\Gamma_{\gamma \gamma}\left(\theta, \gamma^{e}(\theta)\right)=\frac{\varepsilon-1}{[\varepsilon-1+\gamma]^{2}} \frac{\left[1-2\left(1-\theta^{1-1 / \varepsilon}\right](\varepsilon-1) \varepsilon\right.}{\left[2 \varepsilon \gamma\left(1-\theta^{1-1 / \varepsilon}\right)+(1-\gamma)(\varepsilon-1)\right][\varepsilon-1+\gamma]}>0
$$

Since $\Gamma_{\gamma \gamma}>0$ holds for any $\gamma^{e}(\theta) \in(0,1)$, which fulfills $\Gamma_{\gamma}=0$, two conclusions are immediate. First, for any given $\theta \in\left[\theta^{*}, 1\right), \Gamma(\theta, \gamma)$ has a unique local minimum on interval $(0,1)$ and, second, $\Gamma_{\gamma}$ must be positive for any $\gamma \in\left(\gamma^{*}, 1\right)$. Furthermore, it follows from $\Gamma_{\theta}<0$ that $\Gamma(\theta, \gamma)=0$ has a unique solution at $\gamma=\gamma^{e}\left(\theta^{*}\right) \equiv \gamma^{*}$, while it has two solutions if $\theta \in\left(\theta^{*}, 1\right)$ : one in interval $\left(0, \gamma^{*}\right)$ and one in interval $\left(\gamma^{*}, 1\right)$. Hence, we can safely conclude that for any $\eta \in\left(\theta^{*}, 1\right)$, there exists a $\gamma \in\left(\gamma^{*}, 1\right)$, so that $\tilde{\theta}(\gamma)>\eta \cdot{ }^{31}$ This is sufficient for existence of $\lim _{\gamma \rightarrow 1} \tilde{\theta}(\gamma)$ and, due to $\tilde{\theta}(0)=1$ and the continuity of $\tilde{\theta}(\gamma)$ on interval $[0,1)$, it implies that $\tilde{\theta}(\gamma) \rightarrow 1$ if $\gamma \rightarrow 1$.

Step (iii): From step (ii), we know that $d \tilde{\theta}(\gamma) / d \gamma<0$ if $\gamma \in\left[0, \gamma^{*}\right)$ and that $d \tilde{\theta}(\gamma) / d \gamma>0$ for any $\gamma \in\left(\gamma^{*}, 1\right)$. Furthermore, noting $d \tilde{\theta}\left(\gamma^{*}\right) / d \gamma=0$ it follows from (A22) and (A23) that $d^{2} \tilde{\theta}\left(\gamma^{*}\right) / d \gamma^{2}=-\Gamma_{\gamma \gamma} / \Gamma_{\theta}>0 .{ }^{32}$ This confirms that $\gamma^{*}$ is a unique local minimizer of $\tilde{\theta}(\gamma)$ on interval $[0,1)$.

Putting together, steps (i)-(iii) establish the proof for lemma 1. QED

\section{References}

Barth, E., Zweimüller J. (1995), Relative Wages under Decentralized and Corporatist Bargaining Systems, Scandinavian Journal of Economics 97, 369-384.

Barth, E., Lucifora, C., Tsakloglou, P. (2005), Wage Dispersion, Markets and Institutions, unpublished manuscript.

Beissinger, T., Egger, H. (2004), Dynamic Wage Bargaining if Benefits Are Tie to Individual Wages, Oxford Economic Papers 56, 437-460.

Blanchflower D.G., Oswald, A.J., Sanfey, P. (1996), Wages, Profits, and Rent-Sharing, Quarterly Journal of Economics 111, 227-251.

\footnotetext{
${ }^{31}$ Recall that $\Gamma(\theta, 1)>0$ holds for any $\theta \in(0,1)$ and that $\lim _{\theta \rightarrow 1} \Gamma(\theta, 1)=0$.

${ }^{32}$ Note that $\gamma^{*}=\gamma^{e}\left(\theta^{*}\right)$. Then, $\Gamma_{\gamma}\left(\theta^{*}, \gamma^{e}\left(\theta^{*}\right)\right)=0$ and $\Gamma_{\gamma \gamma}\left(\theta^{*}, \gamma^{e}\left(\theta^{*}\right)\right)>0$ follows immediately from the formal analysis in step (ii).
} 
Brainard, S.L. (1997), An Empirical Assessment of the Proximity-Concentration Trade-off between Multinational Sales and Trade, American Economic Review 87, 520-544.

Bughin, J., Vannini, S. (1995), Strategic Direct Investment under Unionized Oligopoly, International Journal of Industrial Organization 13, 127-145.

Caves, R.E. (1996), Multinational Enterprise and Economic Analysis, second edition, New York: Cambridge University Press.

Collie, D., Vandenbussche, H. (2006), Unionization and Outward FDI, Open Economies Review, forthcoming.

Dixit, A.K., Stiglitz, J.E. (1977), Monopolistic Competition and Optimum Product Diversity, American Economic Review 67, 297-308.

Egger, H., Egger, P. (2003), Outsourcing and Skill-Specific Employment in a Small Economy: Austria and the Fall of the Iron Curtain, Oxford Economic Papers 55, 625-643.

Egger, H., Grossmann, V. (2005), Non-Routine Tasks, Restructuring of Firms, and Wage Inequality Within and Between Skill-Groups, Journal of Economics, forthcoming.

Feenstra, R.C., Hanson, G.H. (1999), The impact of outsourcing and high-technology capital on wages: estimates for the United States, 1979-1990, Quarterly Journal of Economics 114, $907-40$.

Fitzenberger, B., Hujer, R., McCurdy, T., Schnabel, R. (2001), Testing for Uniform Wage Trends in West-Germany: A Cohort Analysis Using Quantile Regressions for Censored Data, Empirical Economics 26, 41-86.

Gaston, N. (2002), The Effects of Globalisation on Unions and the Nature of Collective Bargaining, Journal of Economic Integration 17, 377-396.

Helpman, E., Melitz, M., Yeaple, S. (2004), Export versus FDI with Heterogeneous Firms, American Economic Review 94, 300-316.

Hijzen, A., Görg, H., Hine R.C. (2005), International Outsourcing and the Skill Structure of Labour Demand in the United Kingdom, Economic Journal 115, 860-878.

Hildreth, A.K.G. Oswald, A.J. (1997), Rent-Sharing and Wages: Evidence from Company and Establishment Panels, Journal of Labor Economics 15, 318-337. 
Katz, L.F., Autor, D.H. (1999), Changes in the Wage Structure and Earnings Inequality, in: Ashenfelter, O., Card, D. (eds.), Handbook of Labor Economics, Vol. 3A, Amsterdam: Elsevier, 1463- 1555.

Krugman, P.R. (1991), Increasing Returns and Economic Geography, Journal of Political Economy 99, 483-499.

Layard, R., Nickell, S. (1990), Is Unemployment Lower If Unions Bargain Over Employment? Quarterly Journal of Economics 105, 773-787.

Leahy, D., Montagna, C. (2000), Unionisation And Foreign Direct Investment: Challenging Conventional Wisdom?, Economic Journal 110, C80-C92.

Lommerud, K.E., Meland, F., Sørgard, L. (2003), Unionised Oligopoly, Trade liberalization and Location Choice, Economic Journal 113, 782-800.

Markusen J.R. (1984), Multinationals, Multi-Plant Economies, and the Gains from Trade, Journal of International Economics 16, 205-226.

Markusen, J.R. (2002), Multinational Firms and the Theory of International Trade, MIT Press, Cambridge, MA.

Naylor, R., Santoni, M. (2003), Wage Bargaining and Foreign Direct Investment, Journal of International Trade and Economic Development 12, 1-18.

Skaksen J.R. (2004), International Outsourcing when Labour Markets Are Unionized, Canadian Journal of Economics 37, 78-94.

Skaksen M.Y., Sørensen, J.R. (2001), Should Trade Unions Appreciate Foreign Investment, Journal of International Economics 55, 379-390.

Zhao, L. (1995), Cross-Hauling Direct Foreign Investment and Unionized Oligopoly, European Economic Review 39, 1237-1253.

Zhao, L. (1998), The Impact of Foreign Direct Investment on Wages and Employment, Oxford Economic Papers 50, 284-301. 


\section{Supplement to}

\section{Wage Bargaining and Multinational Firms in General Equilibrium}

\section{Proof of proposition 2}

Throughout this proof, we consider $\beta<(\varepsilon-1) /(\varepsilon-1+\gamma)$. Then, the effects of a marginal change in parameter $\phi, \phi=\bar{K}, \bar{L}, N, f, \rho, \gamma, \beta$, on the two labor market variables $u$ and $\tilde{w}$ are determined by

$$
\begin{aligned}
& \frac{d u}{d \phi}=\frac{\partial u}{\partial \phi}+\frac{\partial u}{\partial \mu} \frac{d \mu}{d \phi}+\frac{\partial u}{\partial \theta} \frac{d \theta}{d \phi} \\
& \frac{d \tilde{w}}{d \phi}=\frac{\partial \tilde{w}}{\partial \phi}+\frac{\partial \tilde{w}}{\partial \mu} \frac{d \mu}{d \phi}+\frac{\partial \tilde{w}}{\partial u} \frac{d u}{d \phi}
\end{aligned}
$$

respectively, according to (36) and (42). These comparative static effects are analyzed in detail below.

The impact of a marginal $\bar{K}$ change: A marginal increase of $\bar{K}$ does not have a direct impact on $u$ (for a given $\mu$ ), according to (36). This explains the respective effects for the two scenarios $\Pi(0)<0$ and $\Pi(1)>0$ in table 1 . However, there is an indirect effect through $\mu$ adjustment if $\Pi(0)>0>\Pi(1)$. In this case, we have $d \mu^{\prime} / d \bar{K}>0$, according to proposition 1 . Together with

$$
\frac{\partial u}{\partial \mu}=-\frac{1}{1-\beta} \frac{\varepsilon-1}{\varepsilon-1+\gamma} \frac{\theta\left(1-\theta^{1 / \varepsilon}\right)}{\left[\mu \theta^{1 / \varepsilon}+(1-\mu) \theta\right]^{2}}<0,
$$

this implies $d u / d \bar{K}<0$. With respect to the wage effects, we see from (42) that $\partial \tilde{w} / \partial \bar{K}>0$. Hence, if $\Pi(0)<0$ or $\Pi(1)>0$, so that both $\mu$ and $u$ remain unaffected by marginal changes in $\bar{K}$, we obtain $d \tilde{w} / d \bar{K}>0$. For a parameter domain with $\Pi(0)>0>\Pi(1), \bar{K}$ also exhibits an indirect effect through $\mu$ adjustments. A marginal increase in $\mu$ exhibits, for a given $u$, a negative effect on $\tilde{w}$ and leads to lower unemployment, i.e. $\partial u / \partial \mu<0$. Noting $d \mu / d \bar{K}>0$, according to proposition 1 , it turns out that the indirect effects counteract the direct one, thereby rendering the overall impact of a marginal $\bar{K}$ variation ambiguous if $\Pi(0)>0>\Pi(1)$. We apply numerical simulation techniques to illustrate this result. The respective findings are illustrated in figure S1. ${ }^{1}$ For sufficiently low $\bar{K}$ a marginal increase in the capital endowment exhibits a negative effect on $\tilde{w}$, while the impact becomes positive if $\bar{K}$ sufficiently high.

\footnotetext{
${ }^{1}$ To establish figure S1, the following parameter values have been considered: $\alpha=0.75, \varepsilon=2, \beta=0.01, \rho=4$, $f=1, \gamma=0.8, \bar{L}=1000$ and $N=75$.
} 


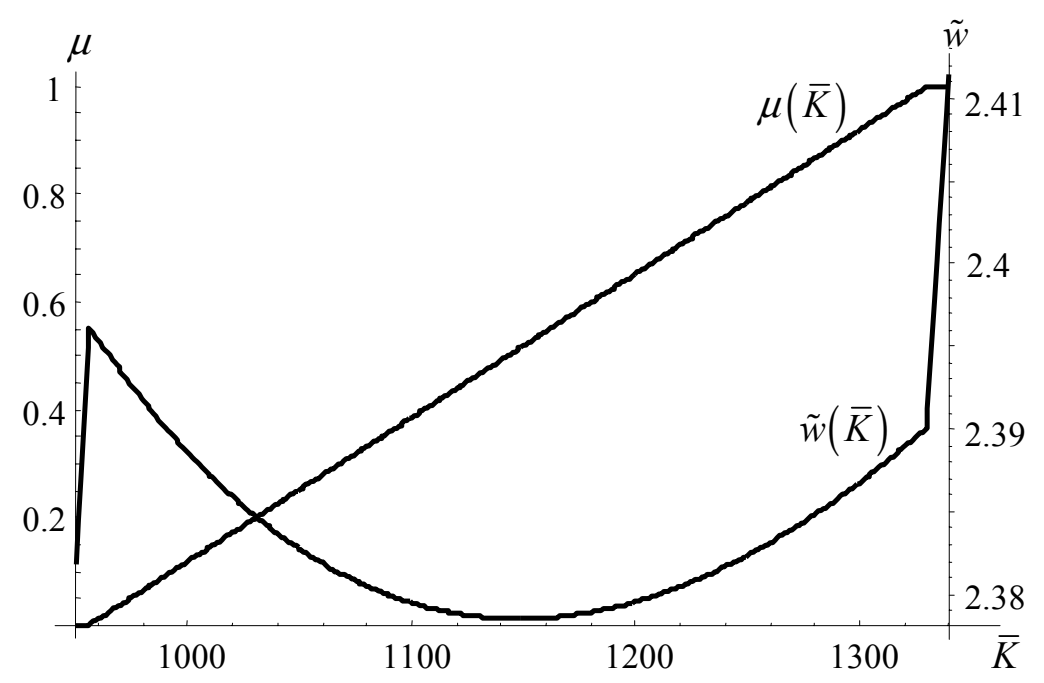

Figure S1: Ambiguous impact of $\bar{K}$ on $\tilde{w}(\bar{K})$

The impact of a marginal $\bar{L}$ change: According to (32), (36) and (46), $\partial u / \partial \bar{L}=d \mu / d \bar{L}=$ $d \theta / d \bar{L}=0$. This implies that an increase of endowment parameter $\bar{L}$ does not exhibit an impact on unemployment rate $u$, according to (S1). Furthermore, it follows from (42) that a higher $\bar{L}$ exhibits a direct negative effect on $\tilde{w}$, so that $d \tilde{w} / d \bar{L}<0$, according to (S2).

The impact of a marginal change in $N$ or $f$ : Since $N$ and $f$ enter as a product in (36) and (42), we can discuss their effects simultaneously, i.e. we focus on the role of $N f$. Noting that changes in $N f$ do not have a direct effect on $u$ and recollecting $d \mu^{\prime} / d(N f)<0$ from proposition 1 , the respective results in table 1 follow from our formal insights above. Furthermore, for a given $\mu$, the direct effect of a marginal $N f$ increase on $\tilde{w}$ is negative, according to (42). However, if a parameter domain with $\Pi(0)>0>\Pi(1)$ prevails, there are indirect effects through $\mu$ adjustments, which counteract the negative direct one. Again, the overall outcome of a marginal $N f$ variation turns out to be ambiguous in this case. This finding is substantiated by figure S2, which illustrates the impact of $N f$ on $\tilde{w}^{2}$ Again, we identify a negative impact on $\tilde{w}$ if $N f$ is sufficiently low and a positive one if $N f$ is sufficiently high. ${ }^{3}$

The impact of a marginal $\rho$ change: Again, $\rho$ does not exhibit a direct impact on unemployment rate $u$. However, a higher $\rho$ leads to a lower $\mu^{\prime}$ if $\Pi(0)>0>\Pi(1)$. In this case, we

\footnotetext{
${ }^{2}$ To establish figure $\mathrm{S} 2$, the following parameter values have been considered: $\alpha=0.75, \varepsilon=2, \beta=0.01$, $\rho=1.008, \gamma=0.5, \bar{L}=1000$ and $\bar{K}=10 \bar{L}$.

${ }^{3}$ Note that $d \tilde{w} / d(N f)$ is positive if $\rho>\theta^{1 / \varepsilon-1}$. This follows from equation (S4) below.
} 


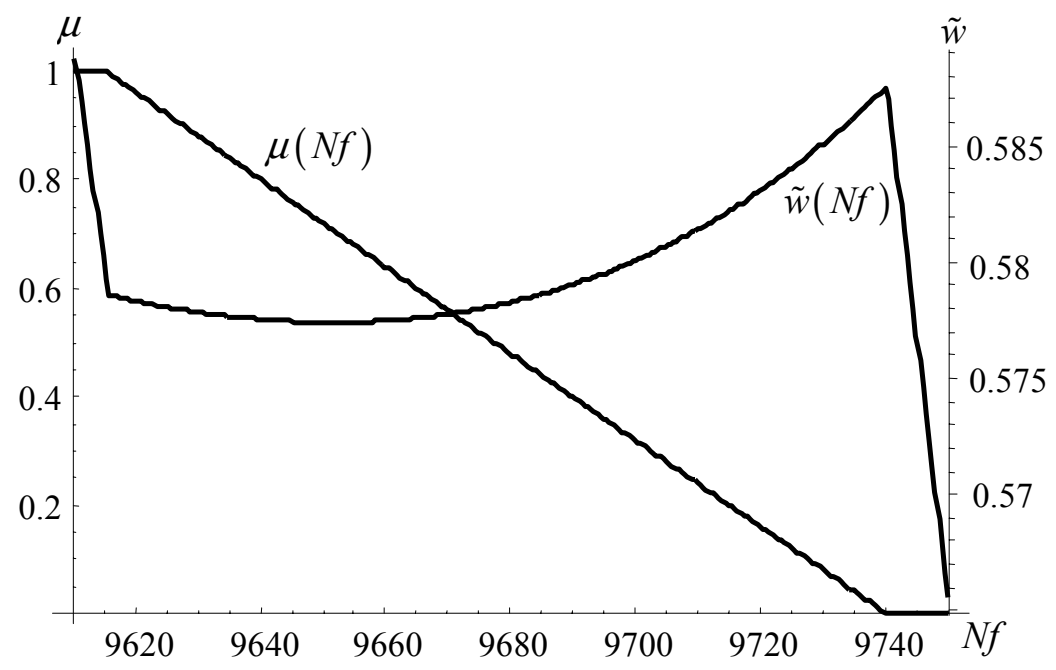

Figure S2: Ambiguous impact of $N f$ on $\tilde{w}$

find $d u / d \rho>0$, according to $(\mathrm{S} 1)$. In a next step, we can differentiate $\tilde{w}$ with respect to $\rho$, this gives $\partial \tilde{w} / \partial \rho=0$ if $\mu=0$ and it gives $\partial \tilde{w} / \partial \rho<0$ if $\mu>0$, according to (42). This proves the respective results for the two scenarios $\Pi(0)<0$ and $\Pi(1)>0$. If a parameter domain with $\Pi(0)>0>\Pi(1)$ prevails, there are indirect effects through $\mu$ adjustment, which counteract the aforementioned direct one. At this stage of our analysis, it is useful to substitute (46) for $\mu$ in (42). This gives

$$
\tilde{w}=\frac{(\varepsilon-1) \zeta}{\zeta+1} \frac{\left[\bar{K}-N f+(\rho-1) N f \theta^{1-1 / \varepsilon} /\left(1-\theta^{1-1 / \varepsilon}\right)\right]}{(1-u) \bar{L}} .
$$

Differentiating (S4) with respect to $\rho$ and noting $\partial \tilde{w} / \partial u>0, d u / d \rho>0$, it is straightforward that $\tilde{w}$ increases in $\rho$ if $\mu \in(0,1)$. This proves the respective finding in table 2 .

The impact of a marginal $\gamma$ change: It is well-known from the autarky case that $\gamma$ exhibits a positive direct effect on $u$. We can use (36) to confirm this result under openness. This explains $d u / d \gamma>0$ if $\Pi(0)<0$. If $\Pi(1)>0$ leads to $\mu=1$, there is an indirect effect through changes in $\theta$. Noting

$$
\frac{\partial u}{\partial \theta}=\frac{1}{(1-\beta)} \frac{\varepsilon-1}{(\varepsilon-1+\gamma)} \frac{1}{\varepsilon \theta^{1+1 / \varepsilon}}>0
$$

it follows from (36) that the overall $\gamma$ effect in a parameter domain with $\Pi(1)>0$ is determined 
by

$$
\frac{d u}{d \gamma}=\frac{1}{1-\beta} \frac{(\varepsilon-1) \theta^{-1 / \varepsilon}}{[\varepsilon-1+\gamma]^{2}}\left[1+\frac{\varepsilon-1+\gamma}{\varepsilon \theta} \frac{d \tilde{\theta}(\gamma)}{d \gamma}\right]
$$

This implies that $d u / d \gamma>,=,<0$ if $[(\varepsilon-1+\gamma) /(\varepsilon \theta)] d \tilde{\theta}(\gamma) / d \gamma>,=,<-1$. To decide upon the sign of $d u / d \gamma$, we recollect equations (A20)-(A22) and calculate

$$
\frac{d \tilde{\theta}(\gamma)}{d \gamma}=\frac{\varepsilon \theta}{\varepsilon-1+\gamma} \frac{2(\varepsilon-1)\left(1-\theta^{1-1 / \varepsilon}\right)(\varepsilon-1+\gamma)-\chi(\theta, \gamma)}{2 \gamma \theta^{1-1 / \varepsilon}(1-\gamma)(\varepsilon-1)^{2}+\chi(\theta, \gamma)}
$$

with

$$
\chi(\theta, \gamma) \equiv\left[2(\varepsilon-1) \gamma\left(1-\theta^{1-1 / \varepsilon}\right)+(1-\gamma)(\varepsilon-1)\right]\left[2 \varepsilon \gamma\left(1-\theta^{1-1 / \varepsilon}\right)+(1-\gamma)(\varepsilon-1)\right] .
$$

It is straightforward that the right-hand side of (S7) is larger than $-\varepsilon \theta /(\varepsilon-1+\gamma)$. This implies $d u / d \gamma>0$ if $\Pi(1)>0$ and confirms the respective result in table 1.

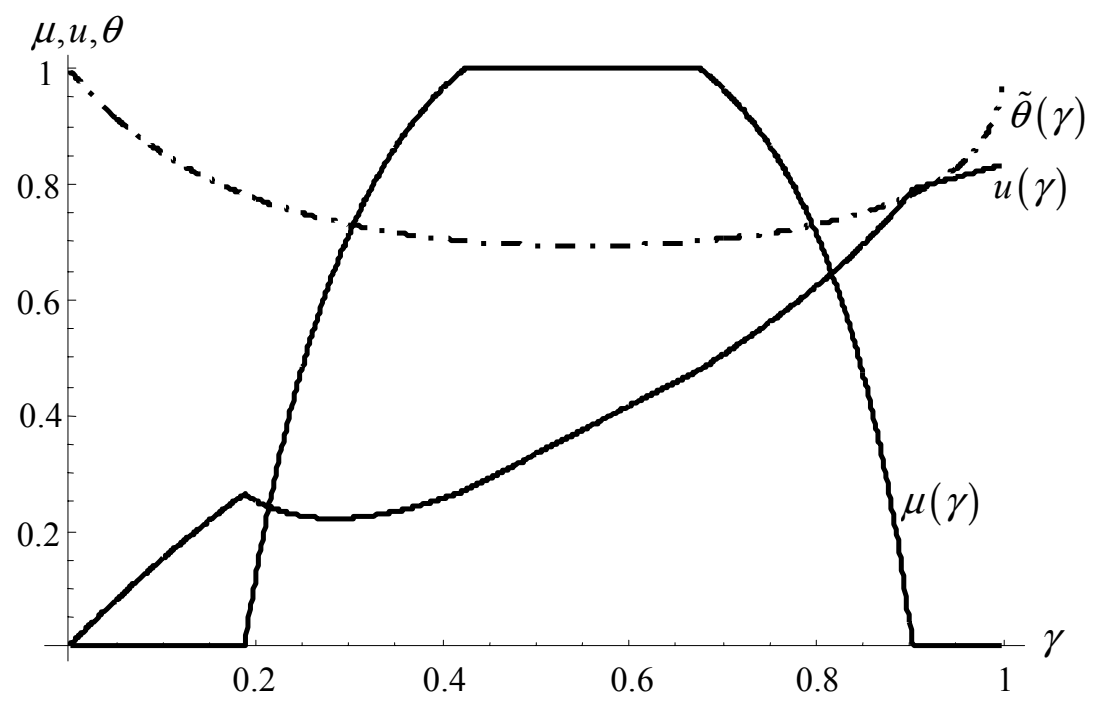

Figure S3: Ambiguous impact of $\gamma$ on $u$

In an intermediate parameter domain with $\Pi(0)>0>\Pi(1)$, there is an additional indirect effect working through changes in $\mu$. According to (S3), we know that $\partial u / \partial \mu<0$. Together with $d \mu / d \theta<0$, this implies that the two indirect effects go into the same direction. If $\gamma \in\left(\gamma^{*}, 1\right)$ this leads to $d u / d \gamma>0$, according to lemma 1. In contrast, if $\gamma \in\left(0, \gamma^{*}\right)$, the two indirect effects counteract the direct one, rendering the overall impact of a marginal $\gamma$ variation ambiguous. 
The ambiguity of the $\gamma$ effect is illustrated in figure S3. ${ }^{4}$

Let us now turn to the wage effects. According to (42), a $\gamma$ change has no impact on $\tilde{w}$ if $\mu$ and $u$ remain unchanged, i.e. $\partial \tilde{w} / \partial \gamma=0$ in $(\mathrm{S} 2)$. This confirms the result for $\Pi(0)<0$. The respective result for $\Pi(1)>0$ directly follows from $\partial \tilde{w} / \partial u>0$ and the unemployment effects outlined above. The firm structure variable does not change in this case. In contrast, if $\Pi(0)>$ $0>\Pi(1)$, there is an additional effect through $\mu$ adjustment. Noting $\partial \tilde{w} / \partial \mu<0$, according to (42), and $\partial u / \partial \mu<0$, according to (S3), and recollecting $d \mu / d \theta<0$ from proposition 1 , it follows from lemma 1 and the unemployment effects outlined above that $d \tilde{w} / d \gamma>0$ if $\gamma \in\left(\gamma^{*}, 1\right)$. Finally, if $\gamma \in\left(0, \gamma^{*}\right)$ its impact on $\tilde{w}$ turns out to be ambiguous. This ambiguity has been confirmed in a numerical simulation analysis, with the main results summarized in figure S4. ${ }^{5}$

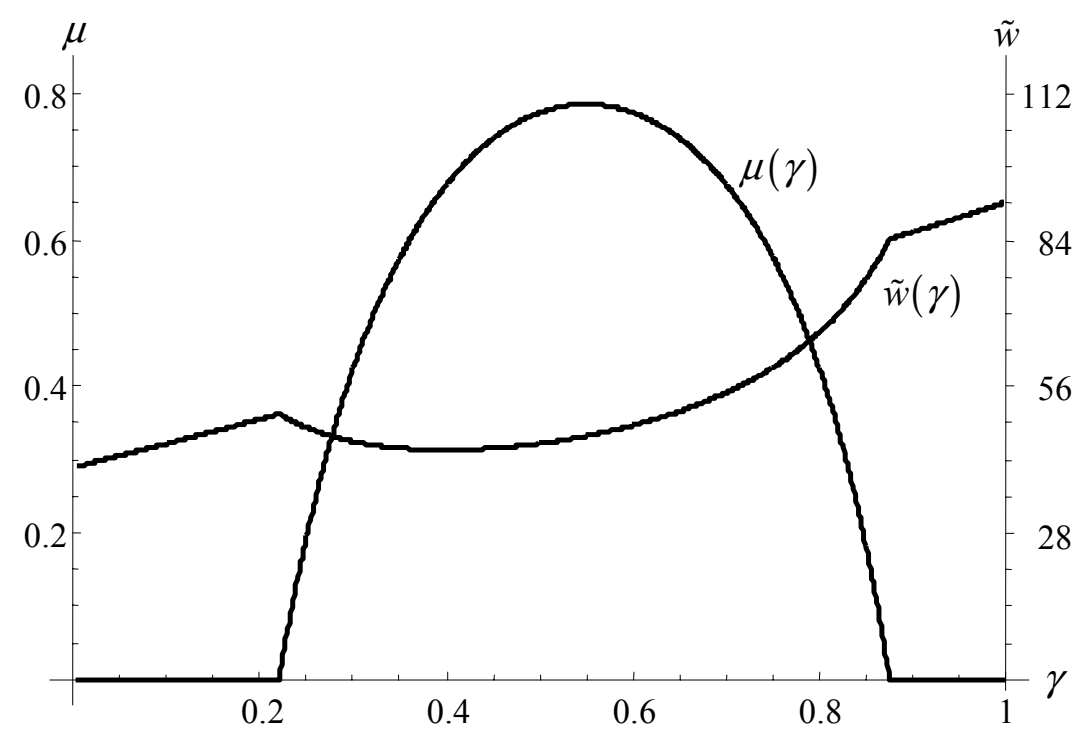

Figure S4: Ambiguous impact of $\gamma$ on $\tilde{w}$

The impact of a marginal $\beta$ change: Variation in the replacement ration $\beta$ has no impact on $\mu$ or $\theta$. Noting further $\partial u / \partial \beta>0, \partial \tilde{w} / \partial \beta=0$ and $\partial \tilde{w} / \partial u>0$, according to (36) and (42), the $\beta$ effects in tables 1 and 2 directly follow. This completes the formal discussion in this supplement.

\footnotetext{
${ }^{4}$ To establish figure S3, the following parameter values have been considered: $\alpha=0.75, \varepsilon=2, \beta=0.40$, $\rho=1.08, f=1000, N=71, \bar{L}=1000$ and $\bar{K}=100 \bar{L}$.

${ }^{5}$ To establish figure $\mathrm{S} 4$, the following parameter values have been considered: $\alpha=0.75, \varepsilon=2, \beta=0.1$, $\rho=1.08, f=1000, N=73, \bar{L}=1000$ and $\bar{K}=100 \bar{L}$.
} 


\section{CESifo Working Paper Series}

(for full list see www.cesifo-group.de)

1649 Anders Forslund, Nils Gottfries and Andreas Westermark, Real and Nominal Wage Adjustment in Open Economies, January 2006

1650 M. Hashem Pesaran, Davide Pettenuzzo and Allan G. Timmermann, Learning, Structural Instability and Present Value Calculations, January 2006

1651 Markku Lanne and Helmut Luetkepohl, Structural Vector Autoregressions with Nonnormal Residuals, January 2006

1652 Helge Berger, Jakob de Haan and Jan-Egbert Sturm, Does Money Matter in the ECB Strategy? New Evidence Based on ECB Communication, January 2006

1653 Axel Dreher and Friedrich Schneider, Corruption and the Shadow Economy: An Empirical Analysis, January 2006

1654 Stefan Brandauer and Florian Englmaier, A Model of Strategic Delegation in Contests between Groups, January 2006

1655 Jan Zápal and Ondřej Schneider, What are their Words Worth? Political Plans and Economic Pains of Fiscal Consolidations in New EU Member States, January 2006

1656 Thiess Buettner, Sebastian Hauptmeier and Robert Schwager, Efficient Revenue Sharing and Upper Level Governments: Theory and Application to Germany, January 2006

1657 Daniel Haile, Abdolkarim Sadrieh and Harrie A. A. Verbon, Cross-Racial Envy and Underinvestment in South Africa, February 2006

1658 Frode Meland and Odd Rune Straume, Outsourcing in Contests, February 2006

1659 M. Hashem Pesaran and Ron Smith, Macroeconometric Modelling with a Global Perspective, February 2006

1660 Alexander F. Wagner and Friedrich Schneider, Satisfaction with Democracy and the Environment in Western Europe - a Panel Analysis, February 2006

1661 Ben J. Heijdra and Jenny E. Ligthart, Fiscal Policy, Monopolistic Competition, and Finite Lives, February 2006

1662 Ludger Woessmann, Public-Private Partnership and Schooling Outcomes across Countries, February 2006

1663 Topi Miettinen and Panu Poutvaara, Political Parties and Network Formation, February 2006 
1664 Alessandro Cigno and Annalisa Luporini, Optimal Policy Towards Families with Different Amounts of Social Capital, in the Presence of Asymmetric Information and Stochastic Fertility, February 2006

1665 Samuel Muehlemann and Stefan C. Wolter, Regional Effects on Employer Provided Training: Evidence from Apprenticeship Training in Switzerland, February 2006

1666 Laszlo Goerke, Bureaucratic Corruption and Profit Tax Evasion, February 2006

1667 Ivo J. M. Arnold and Jan J. G. Lemmen, Inflation Expectations and Inflation Uncertainty in the Eurozone: Evidence from Survey Data, February 2006

1668 Hans Gersbach and Hans Haller, Voice and Bargaining Power, February 2006

1669 Françoise Forges and Frédéric Koessler, Long Persuasion Games, February 2006

1670 Florian Englmaier and Markus Reisinger, Information, Coordination, and the Industrialization of Countries, February 2006

1671 Hendrik Hakenes and Andreas Irmen, Something out of Nothing? Neoclassical Growth and the 'Trivial' Steady State, February 2006

1672 Torsten Persson and Guido Tabellini, Democracy and Development: The Devil in the Details, February 2006

1673 Michael Rauber and Heinrich W. Ursprung, Evaluation of Researchers: A Life Cycle Analysis of German Academic Economists, February 2006

1674 Ernesto Reuben and Frans van Winden, Reciprocity and Emotions when Reciprocators Know each other, February 2006

1675 Assar Lindbeck and Mats Persson, A Model of Income Insurance and Social Norms, February 2006

1676 Horst Raff, Michael Ryan and Frank Staehler, Asset Ownership and Foreign-Market Entry, February 2006

1677 Miguel Portela, Rob Alessie and Coen Teulings, Measurement Error in Education and Growth Regressions, February 2006

1678 Andreas Haufler, Alexander Klemm and Guttorm Schjelderup, Globalisation and the Mix of Wage and Profit Taxes, February 2006

1679 Kurt R. Brekke and Lars Sørgard, Public versus Private Health Care in a National Health Service, March 2006

1680 Dominik Grafenhofer, Christian Jaag, Christian Keuschnigg and Mirela Keuschnigg, Probabilistic Aging, March 2006 
1681 Wladimir Raymond, Pierre Mohnen, Franz Palm and Sybrand Schim van der Loeff, Persistence of Innovation in Dutch Manufacturing: Is it Spurious?, March 2006

1682 Andrea Colciago, V. Anton Muscatelli, Tiziano Ropele and Patrizio Tirelli, The Role of Fiscal Policy in a Monetary Union: Are National Automatic Stabilizers Effective?, March 2006

1683 Mario Jametti and Thomas von Ungern-Sternberg, Risk Selection in Natural Disaster Insurance - the Case of France, March 2006

1684 Ken Sennewald and Klaus Waelde, "Itô's Lemma" and the Bellman Equation for Poisson Processes: An Applied View, March 2006

1685 Ernesto Reuben and Frans van Winden, Negative Reciprocity and the Interaction of Emotions and Fairness Norms, March 2006

1686 Françoise Forges, The Ex Ante Incentive Compatible Core in Exchange Economies with and without Indivisibilities, March 2006

1687 Assar Lindbeck, Mårten Palme and Mats Persson, Job Security and Work Absence: Evidence from a Natural Experiment, March 2006

1688 Sebastian Buhai and Coen Teulings, Tenure Profiles and Efficient Separation in a Stochastic Productivity Model, March 2006

1689 Gebhard Kirchgaessner and Silika Prohl, Sustainability of Swiss Fiscal Policy, March 2006

1690 A. Lans Bovenberg and Peter Birch Sørensen, Optimal Taxation and Social Insurance in a Lifetime Perspective, March 2006

1691 Moritz Schularick and Thomas M. Steger, Does Financial Integration Spur Economic Growth? New Evidence from the First Era of Financial Globalization, March 2006

1692 Burkhard Heer and Alfred Maussner, Business Cycle Dynamics of a New Keynesian Overlapping Generations Model with Progressive Income Taxation, March 2006

1693 Jarko Fidrmuc and Iikka Korhonen, Meta-Analysis of the Business Cycle Correlation between the Euro Area and the CEECs, March 2006

1694 Steffen Henzel and Timo Wollmershaeuser, The New Keynesian Phillips Curve and the Role of Expectations: Evidence from the Ifo World Economic Survey, March 2006

1695 Yin-Wong Cheung, An Empirical Model of Daily Highs and Lows, March 2006

1696 Scott Alan Carson, African-American and White Living Standards in the $19^{\text {th }}$ Century American South: A Biological Comparison, March 2006

1697 Helge Berger, Optimal Central Bank Design: Benchmarks for the ECB, March 2006 
1698 Vjollca Sadiraj, Jan Tuinstra and Frans van Winden, On the Size of the Winning Set in the Presence of Interest Groups, April 2006

1699 Martin Gassebner, Michael Lamla and Jan-Egbert Sturm, Economic, Demographic and Political Determinants of Pollution Reassessed: A Sensitivity Analysis, April 2006

1700 Louis N. Christofides and Amy Chen Peng, Major Provisions of Labour Contracts and their Theoretical Coherence, April 2006

1701 Christian Groth, Karl-Josef Koch and Thomas M. Steger, Rethinking the Concept of Long-Run Economic Growth, April 2006

1702 Dirk Schindler and Guttorm Schjelderup, Company Tax Reform in Europe and its Effect on Collusive Behavior, April 2006

1703 Françoise Forges and Enrico Minelli, Afriat's Theorem for General Budget Sets, April 2006

1704 M. Hashem Pesaran, Ron P. Smith, Takashi Yamagata and Liudmyla Hvozdyk, Pairwise Tests of Purchasing Power Parity Using Aggregate and Disaggregate Price Measures, April 2006

1705 Piero Gottardi and Felix Kubler, Social Security and Risk Sharing, April 2006

1706 Giacomo Corneo and Christina M. Fong, What's the Monetary Value of Distributive Justice?, April 2006

1707 Andreas Knabe, Ronnie Schoeb and Joachim Weimann, Marginal Employment Subsidization: A New Concept and a Reappraisal, April 2006

1708 Hans-Werner Sinn, The Pathological Export Boom and the Bazaar Effect - How to Solve the German Puzzle, April 2006

1709 Helge Berger and Stephan Danninger, The Employment Effects of Labor and Product Markets Deregulation and their Implications for Structural Reform, May 2006

1710 Michael Ehrmann and Marcel Fratzscher, Global Financial Transmission of Monetary Policy Shocks, May 2006

1711 Carsten Eckel and Hartmut Egger, Wage Bargaining and Multinational Firms in General Equilibrium, May 2006 